Article

\title{
Integration of MsrB1 and MsrB2 in the Redox Network during the Development of Orthodox and Recalcitrant Acer Seeds
}

\author{
Ewelina Stolarska $^{1}$, Karolina Bilska $^{1}\left({ }^{10}\right.$, Natalia Wojciechowska ${ }^{1,2}{ }^{\oplus}$, \\ Agnieszka Bagniewska-Zadworna ${ }^{2}\left[\right.$, Pascal Rey ${ }^{3}\left[\right.$ and Ewa M. Kalemba ${ }^{1, *}(\mathbb{C}$ \\ 1 Institute of Dendrology, Polish Academy of Sciences, Parkowa 5, 62-035 Kórnik, Poland; \\ ewelina.stolarska89@gmail.com (E.S.); mgr.karolina.bilska@gmail.com (K.B.); \\ natalia.wojciechowska@amu.edu.pl (N.W.) \\ 2 Department of General Botany, Institute of Experimental Biology, Faculty of Biology, \\ Adam Mickiewicz University, Uniwersytetu Poznańskiego 6, 61-614 Poznań, Poland; agabag@amu.edu.pl \\ 3 Plant Protective Proteins (PPV) Team, Aix Marseille University (AMU), Commissariat à l'Energie Atomique \\ et aux Energies Alternatives (CEA), Centre National de la Recherche Scientifique (CNRS), \\ Biosciences and Biotechnology Institute of Aix-Marseille (BIAM), F-13108 Saint Paul-Lez-Durance, France; \\ pascal.rey@cea.fr \\ * Correspondence: kalemba@man.poznan.pl; Tel.: +48-61-8170033
}

Received: 20 November 2020; Accepted: 7 December 2020; Published: 9 December 2020

check for updates

\begin{abstract}
Two related tree species, Norway maple (Acer platanoides L.) and sycamore (Acer pseudoplatanus L.), produce desiccation-tolerant (orthodox) and desiccation-sensitive (recalcitrant) seeds, respectively. We compared the seeds of these two species to characterize the developmentally driven changes in the levels of peptide-bound methionine sulfoxide (MetO) and the abundance of methionine sulfoxide reductases (Msrs) B1 and B2, with respect to the cellular redox environment. Protein oxidation at the Met level was dynamic only in Norway maple seeds, and the reduced MsrB2 form was detected only in this species. Cell redox status, characterized by the levels of reduced and oxidized ascorbate, glutathione, and nicotinamide adenine dinucleotide (NAD)/phosphate (NADP), was clearly more reduced in the Norway maple seeds than in the sycamore seeds. Clear correlations between MetO levels, changes in water content and redox status were reported in orthodox Acer seeds. The abundance of Msrs was correlated in both species with redox determinants, mainly ascorbate and glutathione. Our data suggest that MsrB2 is associated with the acquisition of desiccation tolerance and that ascorbate might be involved in the redox pathway enabling the regeneration of Msr via intermediates that are not known yet.
\end{abstract}

Keywords: Acer platanoides; Acer pseudoplatanus; ascorbate; glutathione; seed maturation; methionine sulfoxide; methionine sulfoxide reductase; nicotinamide adenine dinucleotide phosphate

\section{Introduction}

Seeds are reproductive structures that evolved to successfully colonize the terrestrial environment by developing important features, including desiccation tolerance and seed dormancy. Seed development begins with fertilized ovules; however, seed morphogenesis, maturation sensu stricto (seed filling) and late seed maturation are the major developmental phases leading to mature embryo formation [1]. Desiccation tolerance is an important physiological trait of seeds, pollen, and resurrection plants. Desiccation tolerance involves the ability to withstand extreme dehydration and to repair damage upon rehydration by activation of protective mechanisms. It is based on the ability of the cell to enter into a quiescent state, fill the vacuole, accumulate protective molecules (sugars, late embryogenesis abundant proteins, heat-shock proteins) and produce antioxidants (reviewed in 
Dekkers et al. [2]). Orthodox seeds are desiccation-tolerant and thus can withstand desiccation to less than $0.07 \mathrm{~g} \mathrm{H}_{2} \mathrm{O} \mathrm{g}^{-1}$ dry weight (DW), intermediate seeds survive dehydration to approximately 0.1-0.2 $\mathrm{g} \mathrm{H}_{2} \mathrm{O} \mathrm{g}^{-1}$, whereas in recalcitrant seeds, which are desiccation-sensitive, the water content (WC) limit ranges from 0.2 to $0.3 \mathrm{~g} \mathrm{H}_{2} \mathrm{O} \mathrm{g}^{-1} \mathrm{DW}$ [3-6]. Orthodox seeds acquire desiccation tolerance during development, whereas recalcitrant seeds are desiccation-sensitive during development and after shedding [3,7]. Transcriptome, genome and proteome analyses have contributed to deciphering mechanisms of desiccation tolerance in seeds [2,8], and many studies have simultaneously examined the phenomenon of recalcitrance [4,9]. Orthodox and recalcitrant seeds differ in terms of several characteristics, e.g., the structural integrity of membranes and organelles after water removal, metabolic shutdown, the antioxidant system, the availability of protectants including sucrose, oligosaccharides, and late embryogenic abundant proteins [4,10].

Seeds of genetically related species of the Acer genus, namely Norway maple (Acer platanoides L.) and sycamore (Acer pseudoplatanus L.), representing orthodox and recalcitrant types, respectively, became a model to study the differences between such contrasted seeds during developmental transitions [11,12] and during drying and desiccation [13-17]. Both Acer species are found in the temperate zone. Despite a small difference in the times of flowering and embryo formation, the DW of their seeds peaks at approximately the same time [18]. During Acer seed development, the redox balance is determined by the activity of the ascorbate-glutathione cycle, and concentrations of mainly glutathione are linked to the acquisition of desiccation tolerance [11]. Developing Acer seeds also differ in proteins sensitive to cysteine oxidation and abundance of peroxiredoxins (Prxs) [12]. The above studies indicated that molecules determining the cellular redox environment should be of special interest for further exploration when defining differences between orthodox and recalcitrant seeds. Because the distinct levels and redox status of pyridine nucleotides, nicotinamide adenine dinucleotide (NAD) and its phosphorylated form (NADP) especially contribute to the orthodox and recalcitrant phenotype of dried Acer seeds [19]. NAD and NADP are crucial coenzymes involved in maintaining the balance between the rates of oxidation and reduction in numerous processes and pathways in plants [20,21], including the plant-specific ascorbate-glutathione cycle [22].

In general, controlled oxidation is a key attribute of the developmental transitions in plants [23], and redox changes are considered seed viability markers [24], and affect many seed traits, including size, dormancy, and sensitivity to aging [23]. Reactive oxygen species (ROS) are dynamically generated in plants (reviewed in Huang et al. [25]), and until their removal, ROS oxidize molecules including proteins. Oxidation of thiol-containing cysteine, sulfur-containing methionine (Met) and nitration of tyrosine (Tyr) are reversible posttranslational modifications considered to participate in redox signaling [26]. Met oxidized to methionine sulfoxide (MetO) is reduced back to Met enzymatically by methionine sulfoxide reductases (Msrs). The (S)- and (R)-stereoisomers of protein-bound MetO are reduced by specific A-type (MsrA) and B-type (MsrB) enzymes, respectively, which are present in many isoforms [27-29]. For example, $14 \mathrm{Msr}$ genes, five $M s r A$ isoforms and nine $M s r B$ isoforms are encoded by the Arabidopsis genome [30,31]. MsrB genes encode proteins with masses of approximately $15 \mathrm{kDa}$. Recently, the accumulation of MsrB was found to be related to the reestablishment of desiccation tolerance in germinating seeds [32], and MsrB2 abundance monitored in gradually drying Norway maple seeds was assumed as an important player of the redox network associated with acquisition of desiccation tolerance [17].

Msrs play protective and signaling roles under many abiotic and biotic stresses (reviewed in Rey and Tarrago [33]). Based on the cis-regulatory elements found in the promoters of $M s r$ genes from Arabidopsis, poplar and rice [30,31], Msrs putatively participate in the regulation of plant growth, including seed development [34]. Experimental studies indicated that plastidial Msrs B1 and B2 contribute to seed longevity [35]. The removal of MetO results in the oxidation of Msrs, which requires thioredoxins and NADPH thioredoxin reductase (TrxR) as electron source in cytosol. In plastids, the reducing power originates from the photosynthetic electron transfer chain via thioredoxins. To function as MetO reductases, Msrs require efficient regeneration to switch between oxidized and reduced forms. MsrB2 and other 2-Cys Msrs are regenerated through a 
thioredoxin (Trx)-dependent mechanism, whereas MsrB1 regeneration uses glutaredoxin (Grx)- and GSH/Grx-dependent mechanisms [36,37]. In this context, the potential reductants of plastidial Msrs remain unknown in seeds, where photosynthesis and thus the Trx-dependent Msr reduction system are probably not active during the maturation phase.

Orthodox and recalcitrant seeds have markedly differing longevities [4], which encouraged us to investigate whether plastidial MsrB isoforms participate in redox regulation during seed development in Norway maple and sycamore. We report that developing Norway maple and sycamore seeds have differing dynamics in terms of MetO levels and MsrB abundance. In addition, the reducing power, which was assessed by pools of reduced and oxidized ascorbate, glutathione, and NAD(P), varied between the two species. Correlation matrixes indicated that ascorbic acid (AsA), GSH and pyridine nucleotides likely drive in concert the redox machinery more efficiently in Norway maple than in sycamore and that AsA could participate in the regeneration of plastidial Msr activity in the context of seed physiology.

\section{Materials and Methods}

\subsection{Plant Material}

Developing seeds of Norway maple and sycamore were used for the study. The seeds were harvested at weekly intervals, starting from the 12th to 23rd weeks after flowering (WAF) (Norway maple) and from the 11th to 22nd WAF (sycamore). The material was collected from single trees localized in Kórnik, western Poland. Water content (WC) measurements were made each harvest day using triplicates of 10 embryonic axes and 5 cotyledons by drying at $105^{\circ} \mathrm{C}$ for $24 \mathrm{~h}$. The same day, the remaining seeds were removed from the seed coat and then weighed and frozen at $-80^{\circ} \mathrm{C}$ in samples of 20 embryonic axes and 5 cotyledons for further analyses.

\subsection{Protein Extraction}

Samples (20 embryonic axes and 5 cotyledons) were ground with liquid nitrogen in a chilled mortar and pestle. The dry powder was incubated with a $50 \mathrm{mM}$ phosphate buffer ( $\mathrm{pH} 7.0)$ and with $2 \%$ polyvinylpolypyrrolidone at $4{ }^{\circ} \mathrm{C}$ for one hour, shaking every $15 \mathrm{~min}$. We applied $300 \mu \mathrm{L}$ of the buffer for each $0.15 \mathrm{~g}$ of seed tissue. The supernatant was collected after centrifugation for $20 \mathrm{~min}$ at $20,000 \times g$ at $4{ }^{\circ} \mathrm{C}$. The protein content was determined by the Bradford method [38].

\subsection{Determination of $\mathrm{MetO}$}

Determinations of MetO, Met, Tyr, and tryptophan (Trp) were performed according to the method described by Baxter et al. [39] using an Agilent Infinity II 1260 model HPLC system (Agilent Technologies, Wilmington, DE, USA) equipped with an Agilent Poroshell 120 Stablebond Aq $(3.0 \times 150 \mathrm{~mm}, 2.7 \mu \mathrm{m})$ particle column heated to $40{ }^{\circ} \mathrm{C}$ and mobile phases based on ultra-pure water (A) and $0.02 \mathrm{M}$ monopotassium phosphate buffer ( $\mathrm{pH} 2.9$ ) combined with $17.5 \%$ acetonitrile and $17.5 \%$ isopropanol (B) in conjunction with an Agilent 1260 Infinity II Diode Array Detector. Proteins isolated in PIPES buffer were digested $\left(20 \mathrm{~h} / 37^{\circ} \mathrm{C}\right)$ using a combination of three enzymes: pronase, leucine aminopeptidase, and prolidase which were obtained from Sigma-Aldrich (St. Louis, MO, USA). The detection wavelengths were $214 \mathrm{~nm}$ (for MetO and Met) and $280 \mathrm{~nm}$ (for Tyr and Trp), with references at $590 \mathrm{~nm}$ (Supplementary Materials Figure S1). The only modifications to the method were adjustments to the model of chromatograph and column. Thus, the elution program was $0 \% \mathrm{~B}$ from 0.0 to $5.0 \mathrm{~min}$ (flow rate of $0.15 \mathrm{~mL} \mathrm{~min}^{-1}$ ), 0 to $16 \% \mathrm{~B}$ from 5.0 to $8.0 \mathrm{~min}$ (flow rate of $0.3 \mathrm{~mL} \mathrm{~min}^{-1}$ ), 16 to $100 \% \mathrm{~B}$ from 8.0 to $16.0 \mathrm{~min}$ (flow rate of $0.3 \mathrm{~mL} \mathrm{~min}^{-1}$ ), and $0 \% \mathrm{~B}$ from 16.0 to $18.0 \mathrm{~min}$ (flow rate from 0.3 to $0.15 \mathrm{~mL} \mathrm{~min}^{-1}$ ). The MetO ratio was calculated in relation to the total pool of Met detected on the basis of calibration curves.

\subsection{Western Blot Analysis}

Samples containing $15 \mu \mathrm{g}$ of protein calculated based on the calibration curve data representing the linear increase between the protein concentration and band intensity were loaded onto a $12 \%$ 
SDS-PAGE gel. The PageRuler Prestained Protein Ladder (Thermo Scientific) was used as the mass marker (Supplementary Materials Figure S2). SDS-PAGE electrophoresis was carried out using the Mini-PROTEAN ${ }^{\circledR}$ Tetra Cell (Bio-Rad Laboratories, Inc., Grand Junction, CO, USA). Separated proteins were transferred to a polyvinylidene fluoride membrane (PVDF, Immobilon-P, Millipore) using a mini trans-Blot ${ }^{\circledR}$ Cell (Bio-Rad) under $350 \mathrm{~mA}$ for $1 \mathrm{~h}$. The PVDF was blocked in $5 \%$ skimmed milk and incubated overnight in primary antibodies (1:1000 dilution) raised against AtMsrB1 and AtMsrB2 [40]. Secondary antibodies were conjugated with alkaline phosphatase (AP, Sigma-Aldrich St. Louis, MO, USA). Protein detection was performed colorimetrically with identical exposure time using 5-bromo-4-chloro-3-indolyl phosphate (Sigma-Aldrich) and tetrazolium blue nitrate (NBT; Sigma-Aldrich) as the AP substrate. Western blot images were analyzed densitometrically in triplicate using the UviBand (UviTec, Cambridge, United Kingdom) program in the Fire Reader Gel Documentation System. Band density was calculated based on the volume (V) of the band as the sum of all 3D intensities (I) coded on a scale of 256 gray levels. The data are presented in relative units obtained from $V=\Sigma n_{i} I$ and the number of pixels inside the area of the band.

\subsection{Immunolocalization}

Cotyledons and embryonic axes were fixed in a mixture of $2 \%$ glutaraldehyde ( $\mathrm{pH} 6.8$; Polysciences, Warrington, USA) and $2 \%(v / v)$ formaldehyde ( $\mathrm{pH} 6.8$; Polysciences) for $12 \mathrm{~h} 4{ }^{\circ} \mathrm{C}$. Then, the material was rinsed three times in 1x PBS (Sigma-Aldrich) buffer. The samples were sectioned ( $30 \mu \mathrm{m})$ using a vibratome Leica VT 1200S (Leica Biosystems). MsrB1 and MsrB2 were localized using primary rabbit antibodies against MsrB1 and MsrB2 at a dilution of 1:100. The tyramide signal amplification (TSA) technique (ThermoFisher Scientific, Carlsbad, CA, USA) was applied because its detection sensitivity is more than 1000 times higher than that of the standard immunolocalization protocol. All steps of the reaction were performed as described by Wojciechowska et al. [41]. The localization results were analyzed and documented with a Leica TCS SP5 confocal microscope (Leica) using an argon laser emitting light at a wavelength of 488 for Alexa Fluor 488. Two negative controls were performed: (1) omitting the primary antibody and (2) omitting antibodies conjugated with HRP. Reactions were carried out on cotyledons and embryonic axes.

\subsection{Determination of NADPH-Dependent Reductases}

Determination of NADPH-dependent reductases was based on the reduction of 5,5'-dithiobis (2-nitrobenzoic) acid (DTNB) with NADPH to 2-nitro-5-thiobenzoate, which produces a strong yellow color that is measured at $412 \mathrm{~nm}$, as described by Alipour et al. [19]. The reaction mixture contained reaction buffer consisting of $50 \mathrm{mM}$ phosphate buffer $\mathrm{pH} 7.0,50 \mathrm{mM} \mathrm{KCl}$, $1 \mathrm{mM}$ ethylenediaminetetraacetic acid (EDTA), $1 \mathrm{mM}$ DTNB, protein extract and $8 \mathrm{mM}$ NADPH. Simultaneously the reaction mixture lacking NADPH was measured to eliminate the reduction of DTNB by thiol-containing components of the measured extract. The reaction was measured for $3 \mathrm{~min}$ using an Infinite M200 PRO (Tecan, Männedorf, Switzerland) plate reader and Magellan software.

\subsection{Determination of Ascorbate, Glutathione and $N A D(P)$ Levels}

The levels of ascorbate, glutathione and $\mathrm{NAD}(\mathrm{P})$ were measured according to the method described by Queval and Noctor [42]. Seed samples were ground in $1 \mathrm{~mL} 0.2 \mathrm{~N} \mathrm{HCl}$ and centrifuged for $10 \mathrm{~min}$ at $4{ }^{\circ} \mathrm{C}$ and $14,000 \mathrm{rpm}$. The extract intended for ascorbate and glutathione determination $(500 \mu \mathrm{L})$ was neutralized and the $\mathrm{pH}$ was adjusted to a $4.5-5$ range. The extract intended for $\mathrm{NAD}(\mathrm{P})$ determination $(200 \mu \mathrm{L})$ was incubated at $100^{\circ} \mathrm{C}$ for $2 \mathrm{~min}$ and neutralized to $\mathrm{pH}$ 6-7 after cooling. The Infinite M200 PRO (Tecan) plate reader and Magellan software were used for all measurements.

For ascorbate determination, the assay was adapted from the methods of Hewitt and Dickes [43] and Queval and Noctor [42] to measure extremely low AsA quantities in drying seeds, and this method is described by Wojciechowska et al. [17]. AsA was measured in neutralized extracts by its ability to absorb light at $265 \mathrm{~nm}$ in a slightly acidic environment. Asc, referred to as "total ascorbate", 
was measured after conversion of DHA to AsA by incubation with $25 \mathrm{mM}$ dithiothreitol at $\mathrm{pH} 4.7$. The measurements were performed in $0.1 \mathrm{mM}$ acetic acetate buffer containing $5 \mathrm{mM}$ EDTA. DHA in the assays was determined by subtracting free AsA from the total AsA.

For determination of glutathione, the neutralized extract was treated with 2-vinylpyridine (2-VP) for $30 \mathrm{~min}$ at $\mathrm{RT}$ and centrifuged twice for $15 \mathrm{~min}$ at $4{ }^{\circ} \mathrm{C}$ and $14,000 \times g$. The reaction mixture contained $120 \mathrm{mM} \mathrm{NaH} \mathrm{PO}_{4} / 10 \mathrm{mM}$ EDTA pH 7.5, 12 mM DTNB, $10 \mathrm{mM}$ NADPH, MQ water and extract (to measure total glutathione, GSH + GSSG) or 2-VP treated extract (to measure GSSG), and glutathione reductase $(0.2 \mathrm{U})$. The kinetic measurements were performed at $412 \mathrm{~nm}$. Calculations were based on calibration curves prepared using GSSG and GSH (Sigma-Aldrich) as standards. The degree of oxidation (DO) of glutathione was calculated according to Meyer and Hell [44].

For determination of NAD(P) pools, the reaction mixture consisted of $10 \mathrm{mM}$ HEPES/2 mM EDTA (pH 7.5), $1.2 \mathrm{mM}$ 2,6-dichlorophenolindophenol, $10 \mathrm{mM}$ phenazine methosulfate, and neutralized extracts. Glucose-6-phosphate dehydrogenase (2 U) and $10 \mathrm{mM}$ glucose-6-phosphate were added to measure NADP. Alcohol dehydrogenase $(25 \mathrm{U})$ and ethanol were added to measure NAD. The kinetic measurements were performed at $340 \mathrm{~nm}$. The levels of reduced and oxidized forms of NAD(P) were calculated based on calibration curves prepared using NADPH, NADP ${ }^{+}, \mathrm{NADH}$ and NAD ${ }^{+}$ (Sigma-Aldrich) as standards.

\subsection{Statistical Analyses}

Data are the means of three independent replicates \pm the standard deviation (STD) or standard error (SE). Statistically significant differences are indicated with different letters (one-way ANOVA, followed by Tukey's test at $p \leq 0.05$ ). The relationships between particular parameters were examined using Pearson's correlation coefficient analysis. Proportional data were transformed prior to analysis using the arcsine transformation. R statistical software was used to calculate Pearson's correlation [45]. Correlation matrixes were made using the corrplot package [46].

\section{Results}

\subsection{Changes in Seed Hydration Levels}

Seed development was analyzed from the 12th to 23rd WAF in Norway maple and from the 11th to 22nd WAF in sycamore. The WC gradually decreased as seeds of both species matured (Figure 1). At the beginning of development, the embryonic axes and cotyledons of Norway maple were more hydrated than those of sycamore. In contrast, at the end of maturation, the level of hydration in Norway maple seeds was lower than that in sycamore seeds. Thus, 12 weeks of seed development and maturation resulted in WC decreases of $\sim 29 \%$ and $\sim 19 \%$ in the embryonic axes of Norway maple and sycamore, respectively (Figure 1A). In the cotyledons of sycamore, the loss of water reached $\sim 23 \%$, compared to $\sim 33 \%$ in the cotyledons of Norway maple (Figure $1 \mathrm{~B}$ ). The changes in seed hydration were reflected in the changes in DW in both the embryonic axes (Figure 1A) and cotyledons (Figure 1B).

\subsection{Protein and Peptide-Bound MetO Content}

The level of soluble proteins increased as maturation progressed, particularly in cotyledons (Supplementary Materials Figure S3). After the 17th WAF, protein abundance increased up to $80 \mathrm{mg}$ per $g$ DW during maturation. Sycamore cotyledons accumulated significantly more proteins than Norway maple cotyledons. Similarly, the amount of proteins was higher in the sycamore embryonic axes than in the Norway maple embryonic axes. The peptide-bound MetO levels did not change in developing sycamore seeds, whereas in Norway maple seeds, significant changes were reported (Figure 2). The highest MetO level was detected at the 14th and 20th WAF in embryonic axes and at the 16th WAF in cotyledons. Interestingly, the developmental stage with the greatest difference between the MetO levels in the embryonic axes and cotyledons corresponded to the 20th WAF (Figure 2). 
A

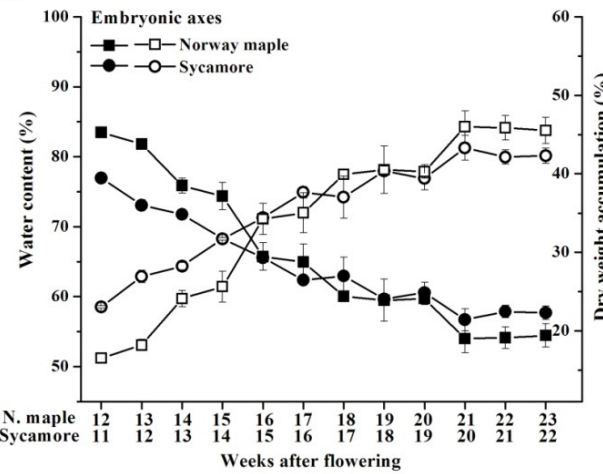

B

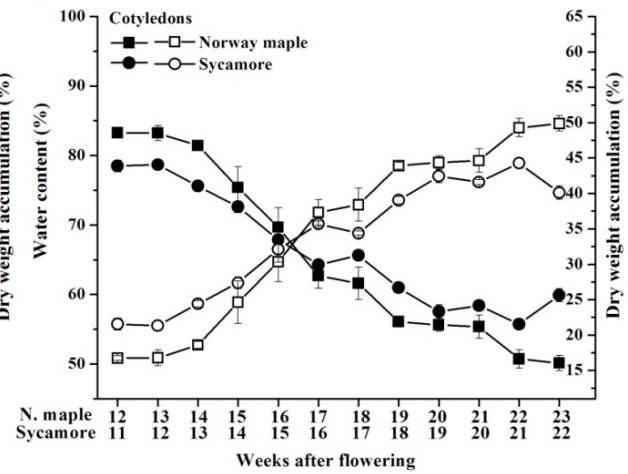

Figure 1. Changes in water content (solid symbol) and dry mass accumulation (open symbol) in the embryonic axes (A) and cotyledons (B) of developing seeds of Norway maple (squares) and sycamore (circles) collected during the 11th-23rd weeks after flowering. Data are the means of three independent replicates \pm the standard deviation.
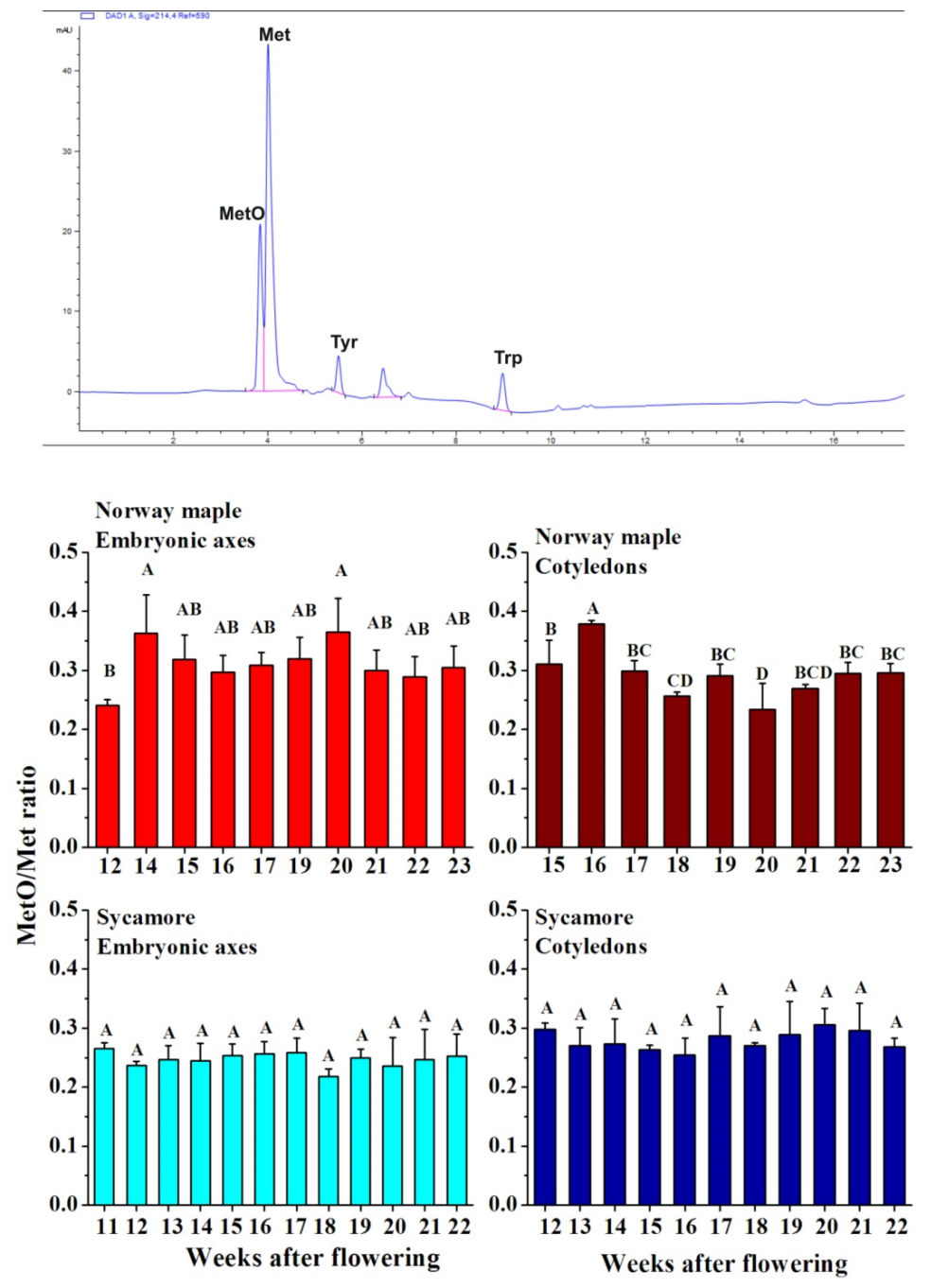

Figure 2. Detection of methionine (Met) oxidized to methionine sulfoxide (MetO) in proteins of developing Norway maple and sycamore seeds collected during the 11th-23rd weeks after flowering. A representative chromatogram indicating peaks recognized at $214 \mathrm{~nm}$ is given. Standards of Met, MetO, tyrosine (Tyr) and tryptophan (Trp) were used for the calibration curves. The MetO ratio was calculated in relation to the total pool of methionine. Data are the means of three independent replicates \pm the standard deviation. Identical letters indicate groups not significantly differentiated according to Tukey's test. 


\subsection{Abundance of MsrB1 and MsrB2 Proteins}

The abundance of the two plastidial B-type MSR isoforms, MsrB1 and MsrB2, was investigated in Acer seeds (Figure 3). MsrB1 was detected uniquely in sycamore as a $17 \mathrm{kDa}$ protein (Figure S4). In embryonic axes, detectable amounts were revealed at the 13th WAF, whereas in cotyledons, MsrB1 was detectable one week earlier, and the protein was present in larger amounts throughout the whole development and during the maturation phase (Figure 3A). Interestingly, a linear increase in the amount of MsrB1 was observed at the 12th-17th WAF in cotyledons. In embryonic axes, an increased abundance of MsrB1 was detected at the 15th-17th WAF. MsrB2 was detectable in seeds of both Acer species. In sycamore, MsrB2 was detectable uniquely in the embryonic axes as a one-protein band with a molecular mass of $14 \mathrm{kDa}$ (Figure 3B, Supplementary Materials Figure S4).

A

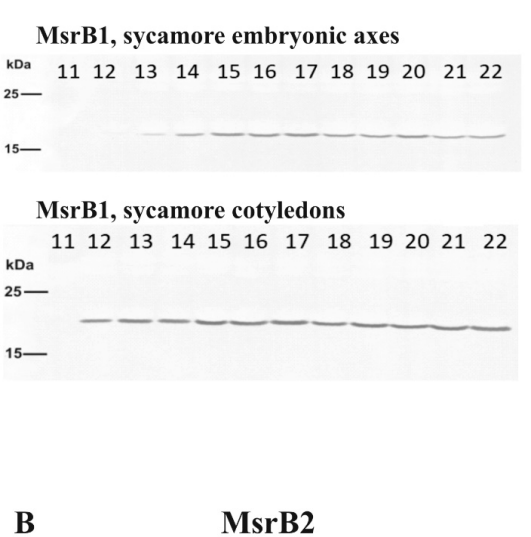

\section{MsrB1}

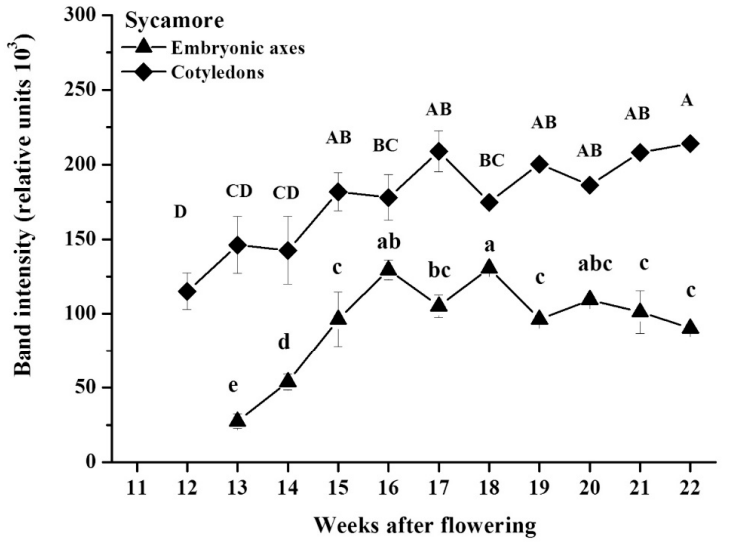

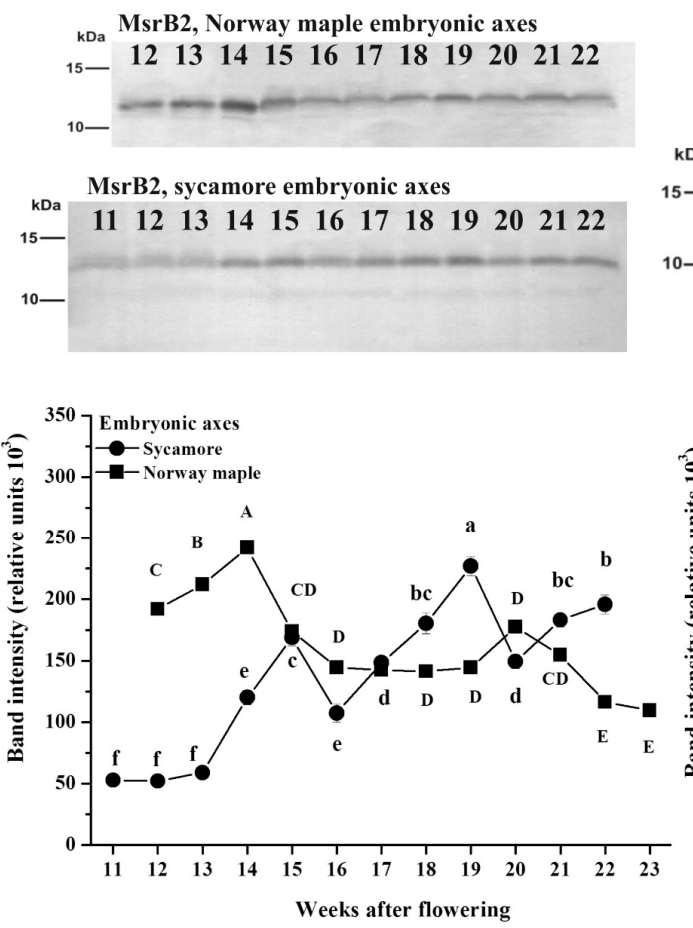
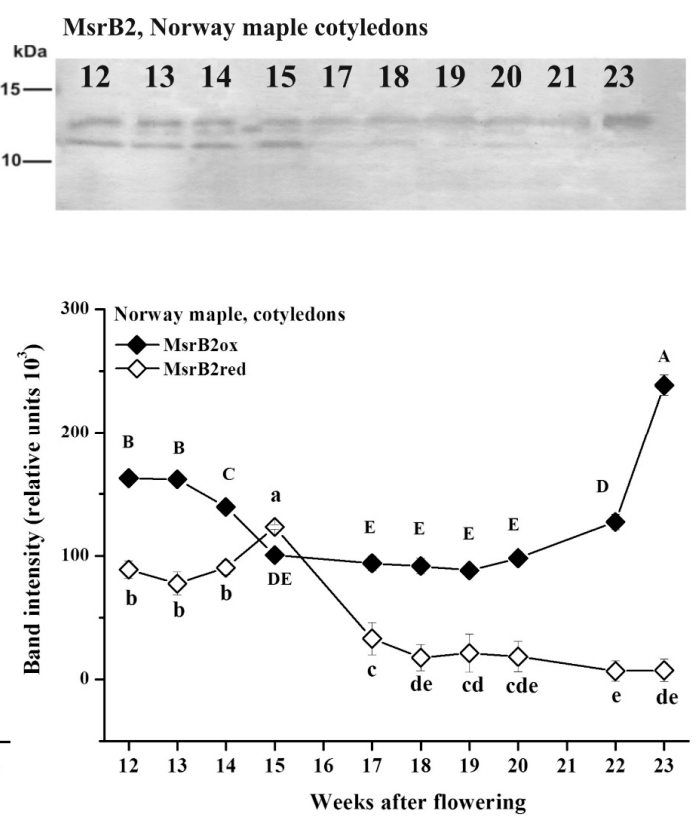

Figure 3. Immunodetection of MsrB1 (A) and MsrB2 (B) proteins in embryonic axes and cotyledons of Norway maple and sycamore seeds collected during the 11th-23rd weeks after flowering. Representative Western blots are given. Samples containing $15 \mu \mathrm{g}$ of protein were loaded per lane. Antibodies against AtMsrB1 and AtMsrB2 were used. The molecular mass was estimated based on PageRuler Prestained Protein Ladder (Thermo Scientific). Identical letters indicate groups not significantly different according to Tukey's test. 
In Norway maple, this protein was present in both the embryonic axes and cotyledons and was present in two different redox forms with molecular masses of 12 and $13 \mathrm{kDa}$ [40]. A greater amount of MsrB2 was revealed in embryonic axes at the 14th WAF. The two redox MsrB2 forms were revealed in cotyledons at the 12th-16th WAF. During later stages, the $12 \mathrm{kDa}$ form was hardly detectable in the cotyledons, and the protein abundance decreased. In embryonic axes, higher amounts of MsrB2 were noticed in Norway maple than in sycamore. Immunohistochemistry was performed to detect whether the MsrB1 protein might be expressed at levels undetectable by the Western blot method. Using confocal laser scanning microscopy and signal enhancement, both MsrB proteins were detected within embryonic axes and cotyledons of both species (Figure 4). In most organs, MsrB2 was found more abundant than MsrB1 [30,40]. According to the Protein Abundance Database (PaxDb) 4.1, in Arabidopsis thaliana, the whole-organism MsrB1 protein abundance, expressed in parts per million (ppm), is four orders of magnitude lower than that of the whole-organism MsrB2 abundance. This fact might explain why MsrB1 was undetectable using standard Western blot analysis (Figure 3A) and detectable using the TSA signal enhancer in confocal microscopy (Figure 4).
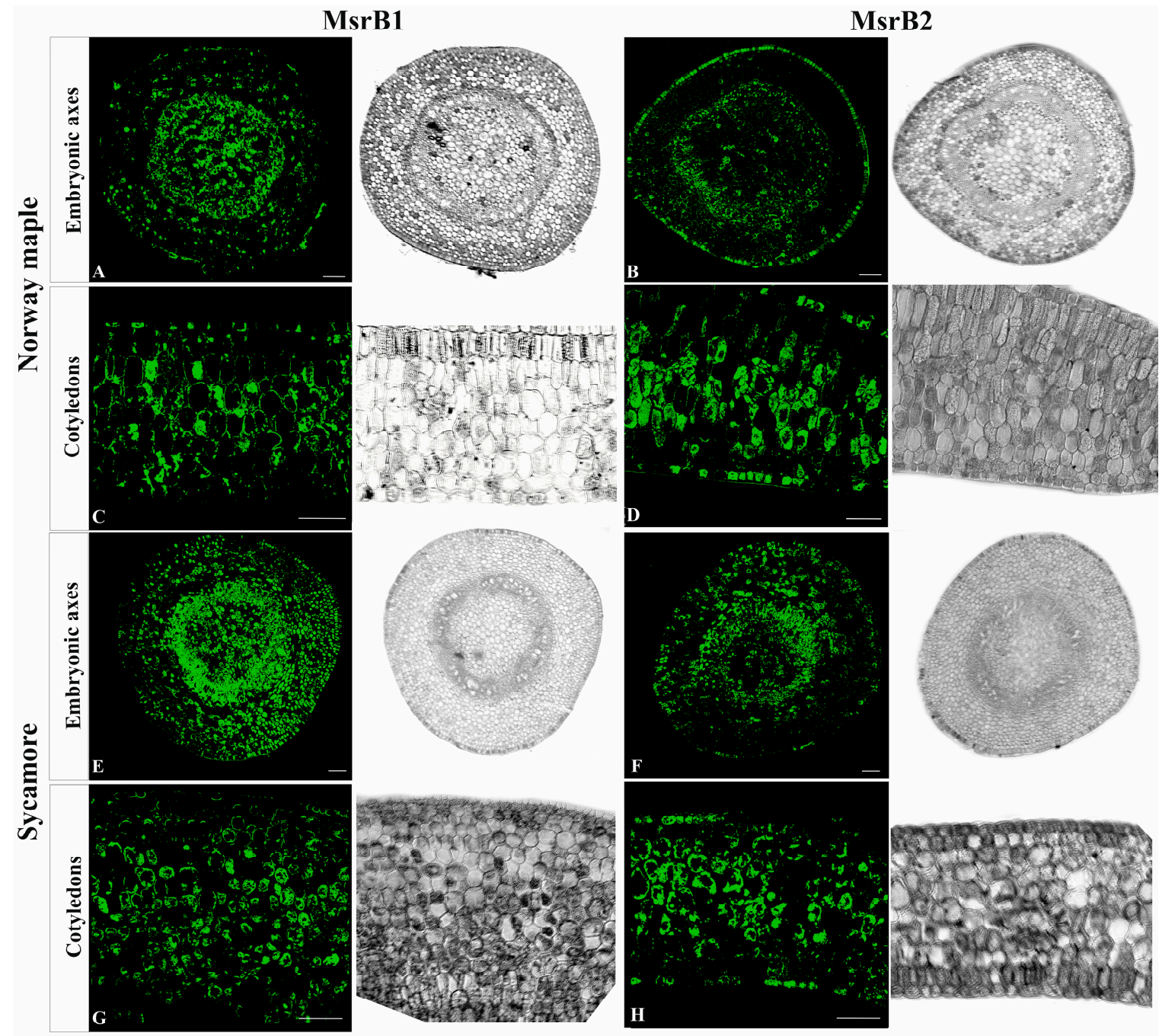

Figure 4. Immunohistochemical localization (green fluorescence) of MsrB1 and MsrB2 proteins in the embryonic axes $(\mathbf{A}, \mathbf{B})$ and cotyledons $(\mathbf{C}, \mathbf{D})$ of mature Norway maple seeds and in the embryonic axes $(\mathbf{E}, \mathbf{F})$ and cotyledons $(\mathbf{G}, \mathbf{H})$ of mature sycamore seeds. Bars $=100 \mu \mathrm{m}$.

Two negative controls were performed: (1) omitting the primary antibody and (2) omitting antibodies conjugated with HRP. Reactions carried out on embryonic axes and cotyledons of both species confirmed specificity of primary antibodies (Figure 5). 


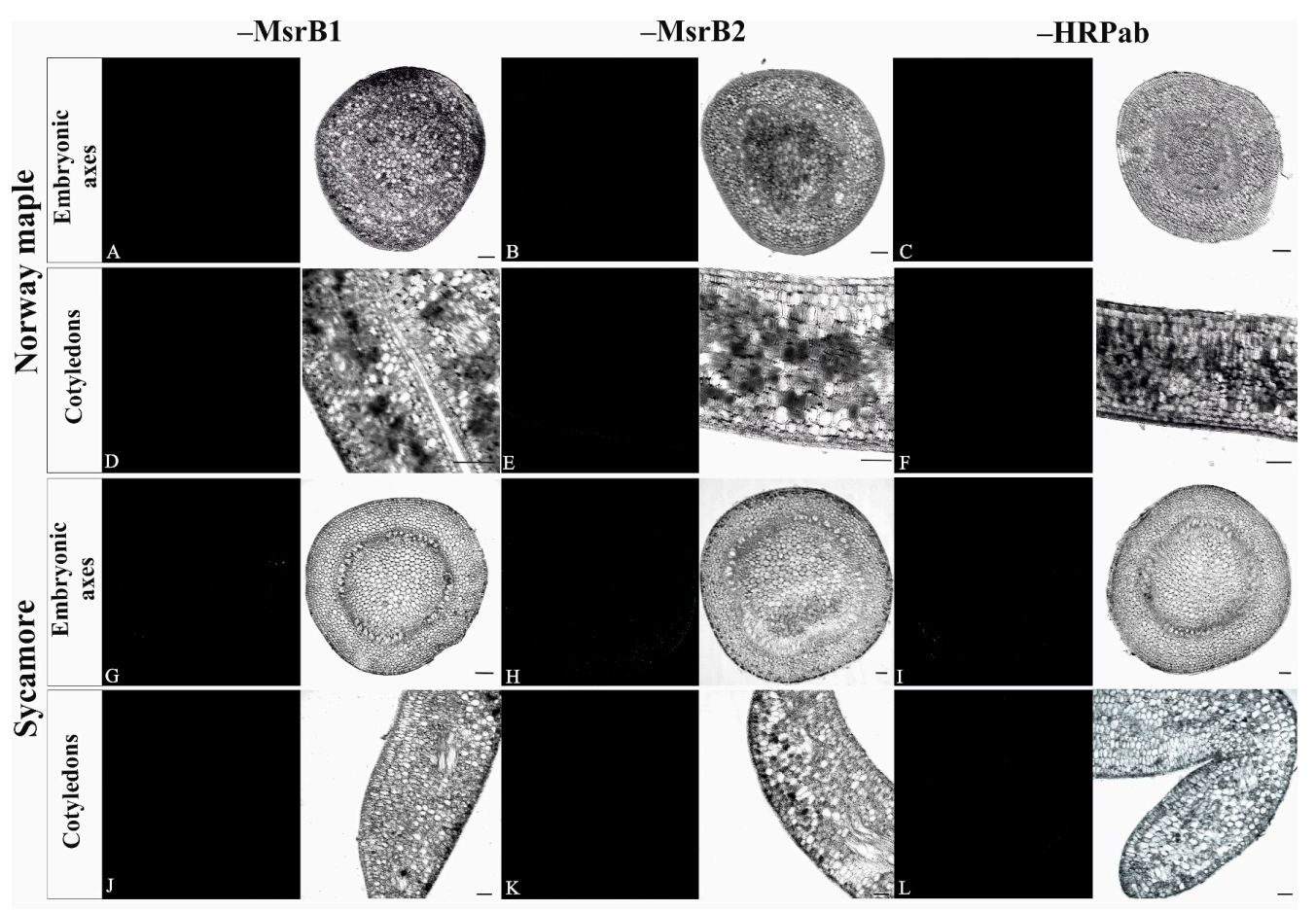

Figure 5. Negative controls for immunohistochemical reactions of MsrB1 and MsrB2 localization, performed on embryonic axes and cotyledons of Norway maple and sycamore seeds. The reactions were performed omitting: the primary antibody MsrB1 (A,D,G,J), the primary antibody MsrB2 (B,E,H,K), and the secondary antibody HRPab conjugated with horseradish peroxidase $(\mathbf{C}, \mathbf{F}, \mathbf{I}, \mathbf{L})$. For each reaction image an corresponding image in bright light is given.

\subsection{Activity of NADPH-Dependent Reductases}

The activity of NADPH-dependent reductases was higher in Norway maple seeds than in sycamore seeds (Figure 6). In Norway maple, the highest activity was reported at the 15th WAF in both embryonic axes and cotyledons, although this peak was nearly two-fold lower in cotyledons than in embryonic axes. In sycamore, the peak in activity of NADPH-dependent reductases was also detected in embryonic axes at the 15th WAF but was 3-fold lower than the peak observed in Norway maple. In the sycamore cotyledons, the highest activity was measured at the 16th WAF and was two-fold lower than the highest activity in the cotyledons of Norway maple.
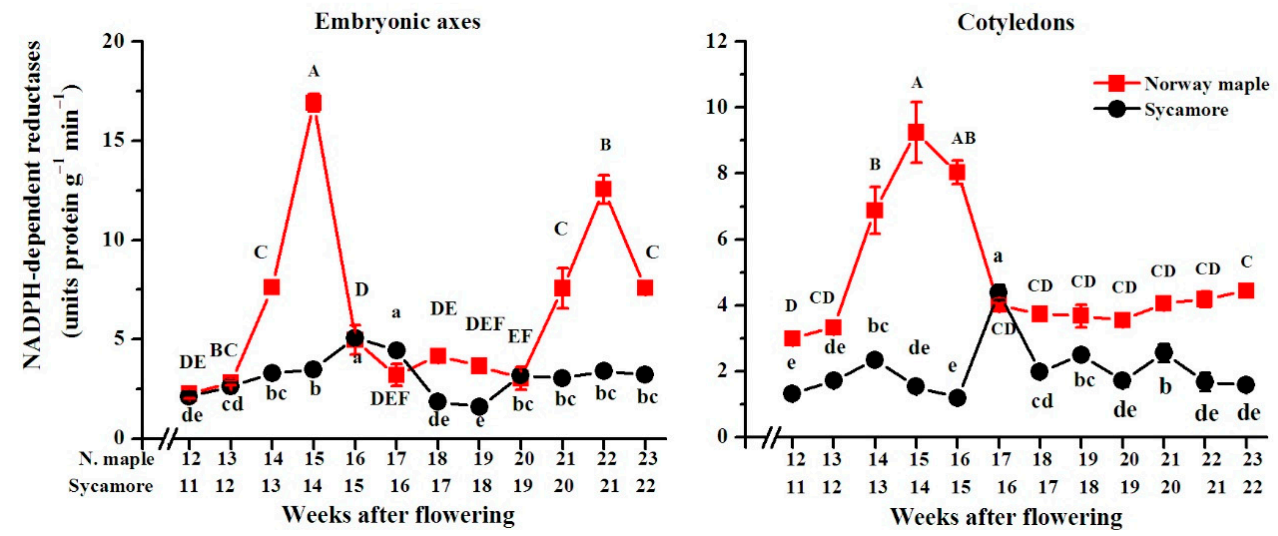

Figure 6. Changes in the activity of total NADPH-dependent reductases reported in the embryonic axes and cotyledons of developing seeds of Norway maple (squares) and sycamore (circles) collected during the 11th-23rd weeks after flowering. Data are the means of three independent replicates \pm the standard error. Statistically significant differences are indicated with different letters (one-way ANOVA, followed by Tukey's test at $p<0.05)$. The capital letters refer to Norway maple. 


\section{5. $N A D(P)$ Content}

The pool of NAD in the embryonic axes of Norway maple seeds was the highest at the morphogenesis stage, subsequently decreased, peaked at the 17th WAF and reached the lowest values at the end of maturation at the 20th-23rd WAF (Figure 7). The average concentrations of NAD in cotyledons were comparable to those in embryonic axes at the 12th-15th WAF, and then markedly decreased up to ten times, reaching the lowest values at the 16th-19th WAF. Then, the NAD concentration increased five times and remained nearly constant to the end of maturation. The NAD concentration in the embryonic axes of sycamore seeds did not vary significantly, except for at the 12th WAF, when the pool of NAD doubled and increased until the 22nd WAF at the end of maturation. In sycamore cotyledons, the NAD concentration remained at approximately $125 \mathrm{nmol} \mathrm{g}^{-1} \mathrm{DW}$, except for at the 15th and 19th WAF, when maximal values were detected, and except for the period between the two peaks, i.e., at the 16th-18th WAF, when significantly low NAD concentrations were measured.

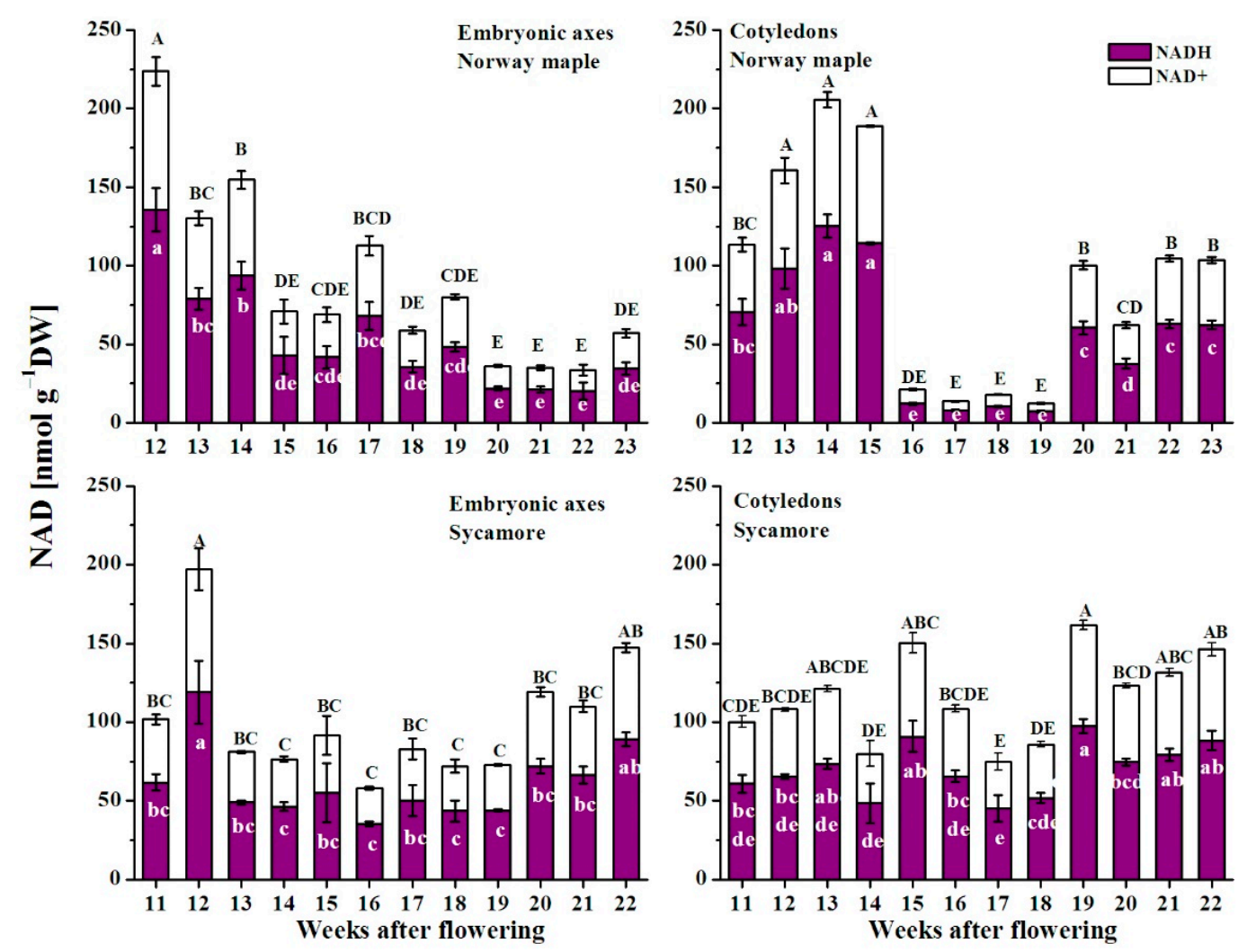

Figure 7. Changes in the levels of the reduced (NADH) and oxidized $\left(\mathrm{NAD}^{+}\right)$forms of nicotinamide adenine dinucleotide (NAD) in the embryonic axes and cotyledons of developing seeds of Norway maple and sycamore collected during the 11th-23rd weeks after flowering. Data are the means of three independent replicates \pm the standard error. Statistically significant differences are indicated with letters (one-way ANOVA, followed by Tukey's test at $p<0.05$ ). The capital letters refer to NAD ${ }^{+}$.

The NADP pool was up to three times higher in Norway maple seeds than in sycamore seeds (Figure 8). Three clear peaks of NADP were reported in Norway maple embryonic axes at the 16th, 19th and 21st WAF, whereas in cotyledons, the NADP level was relatively stable at the first morphogenesis stages, exhibiting concentrations approximately three times higher than those during the maturation stages. The highest concentration of NADP in the sycamore embryonic axes was observed at the 12th WAF, after which the NADP concentration decreased until the 16th WAF and then peaked again at the 18th WAF to a level that was sustained to the end of maturation. The changes in NADP concentration in sycamore cotyledons globally reflected those in NAD concentration. 

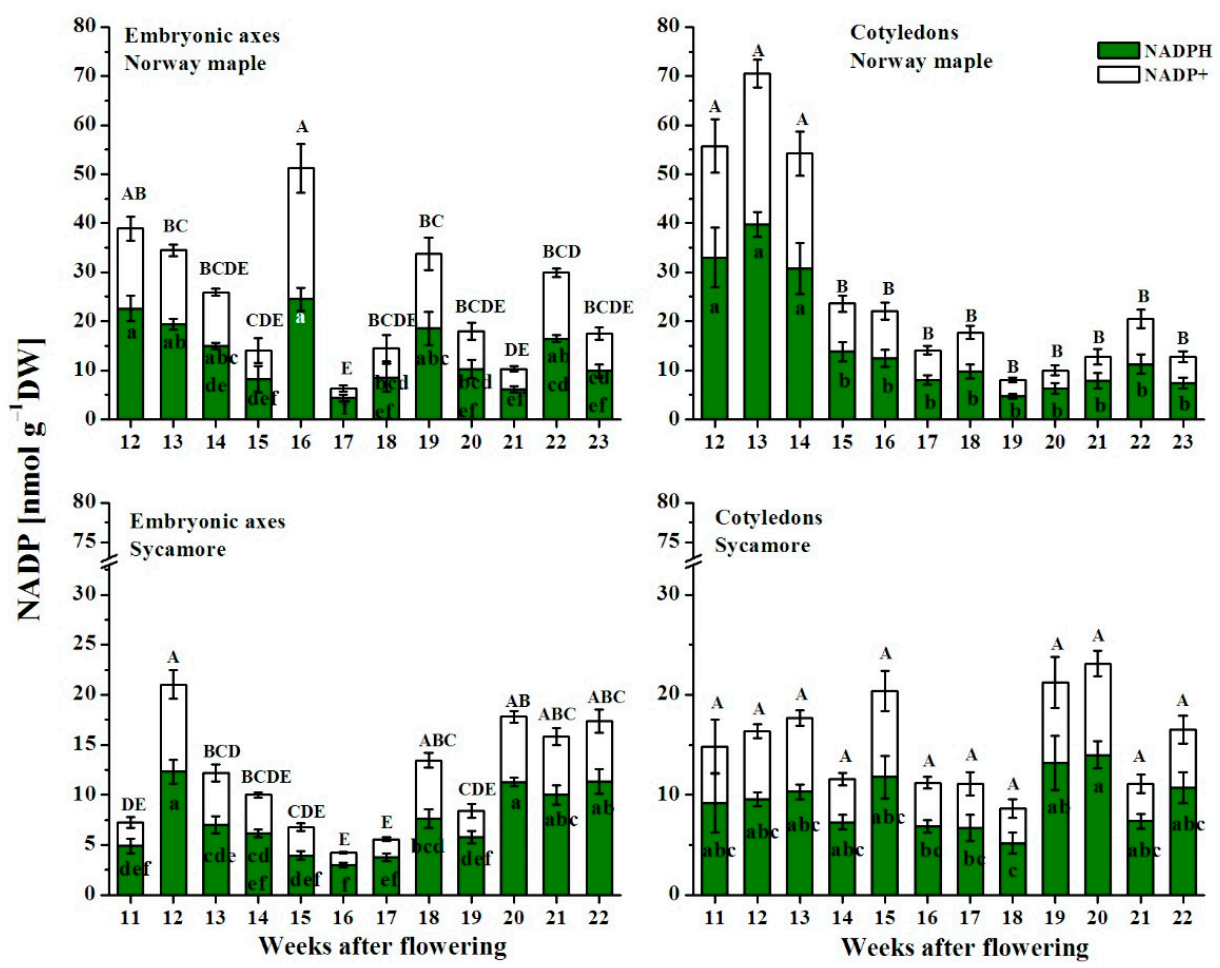

Figure 8. Changes in the levels of the reduced (NADPH) and oxidized $\left(\mathrm{NADP}^{+}\right)$forms of nicotinamide adenine dinucleotide phosphate (NADP) in the embryonic axes and cotyledons of the developing seeds of Norway maple and sycamore collected during the 11th-23rd weeks after flowering. Data are the means of three independent replicates \pm the standard error. Statistically significant differences are indicated with different letters (one-way ANOVA, followed by Tukey's test at $p<0.05$ ). The capital letters refer to $\mathrm{NADP}^{+}$.

The NADH/NAD ${ }^{+}$ratio (Figure $9 \mathrm{~A}$ ) in the embryonic axes of Norway maple was stable during the whole analyzed period, reaching $~ 1.5$, whereas in cotyledons, the highest ratio was detected at the 12th WAF. A significantly decreased $\mathrm{NADH} / \mathrm{NAD}^{+}$ratio occurred in the four following weeks between the 16th and 19th WAF. Afterward, the ratio returned to its original level. The $\mathrm{NADH} / \mathrm{NAD}^{+}$ratio displayed discrete changes in both the embryonic axes and cotyledons of sycamore. The NAD(P)H/NAD $(P)^{+}$ ratios in both Acer species were higher than 1 (Figure 9). Sycamore cotyledons were characterized by a slightly higher NADPH/NADP ${ }^{+}$ratio than Norway maple cotyledons (Figure 9B). The NADPH/NADP ${ }^{+}$ ratio reported in the embryonic axes of Norway maple was quite stable until the 15th WAF, decreased slightly to $\sim 1.0$ at the 16th WAF, and subsequently increased to $\sim 2.7$ at the 17th WAF. Afterward, the ratio decreased to $\sim 1.5$ and remained stable until the $23 \mathrm{rd}$ WAF. The NADPH/NADP ${ }^{+}$ratio measured in the sycamore embryonic axes was quite stable; however, two peaks were noticed at the 11th and 19th WAF when the ratio reached 3.0.

\subsection{Ascorbate Content}

The Asc pool, which includes reduced ascorbate (AsA) and DHA, the oxidized form of AsA, decreased approximately four times in the embryonic axes and approximately ten times in the cotyledons of Norway maple during the studied developmental period, whereas in sycamore seeds, the Asc pool was halved in cotyledons and only slightly reduced in embryonic axes (Figure 10). The concentration of Asc clearly decreased during Norway maple seed development until the 18th WAF, and then remained at a stable level, which was higher in embryonic axes than in cotyledons. DHA was predominant, particularly in embryonic axes, in the last stages of Norway maple seed development, whereas in sycamore seeds, DHA was more abundant than AsA during the whole developmental period. 
A

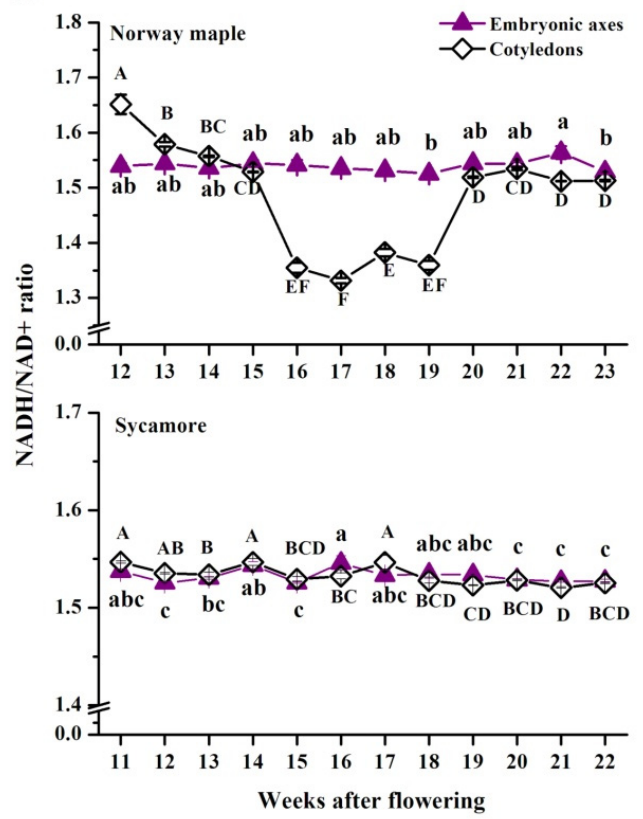

B

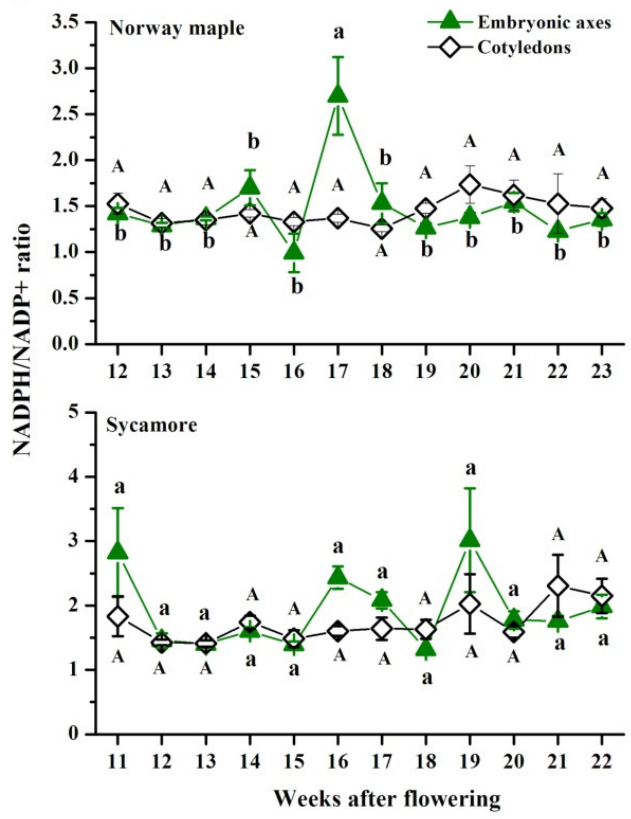

Figure 9. Changes in the ratios of $(\mathrm{A})$ reduced (NADH) to oxidized $\left(\mathrm{NAD}^{+}\right)$forms of nicotinamide adenine dinucleotide (NAD) and $(\mathbf{B})$ reduced $(\mathrm{NADPH})$ to oxidized $\left(\mathrm{NADP}^{+}\right)$forms of nicotinamide adenine dinucleotide phosphate (NADP) in the embryonic axes and cotyledons of the developing seeds of Norway maple and sycamore collected during the 11th-23rd weeks after flowering. Data are the means of three independent replicates \pm the standard error. Statistically significant differences are indicated with different letters (one-way ANOVA, followed by Tukey's test at $p<0.05$ ). The capital letters refer to the embryonic axes.
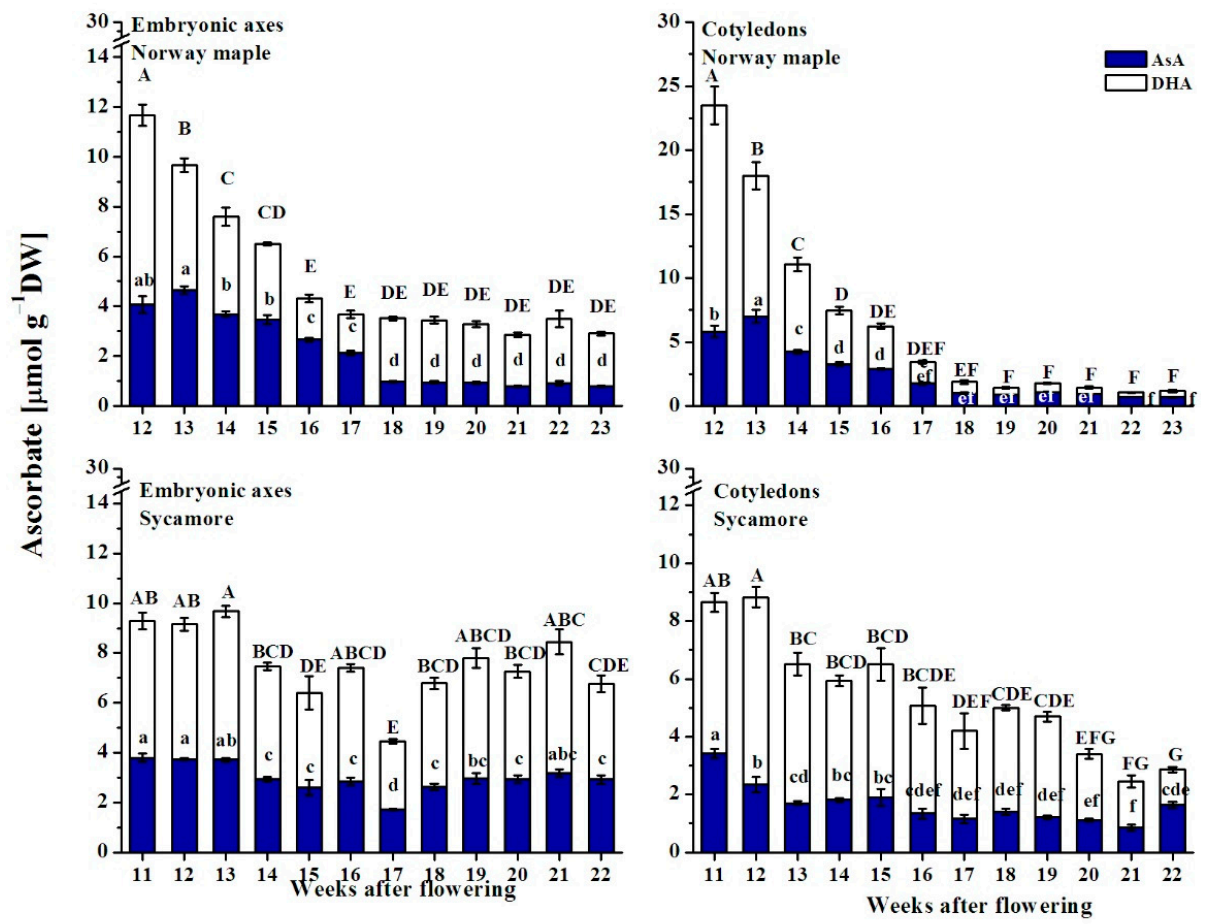

Figure 10. Changes in the levels of the reduced (AsA) and oxidized (DHA) forms of ascorbate reported in the embryonic axes and cotyledons of the developing seeds of Norway maple and sycamore collected during the 11th-23rd weeks after flowering. Data are the means of three independent replicates \pm the standard error. Statistically significant differences are indicated with different letters (one-way ANOVA, followed by Tukey's test at $p<0.05)$. The capital letters refer to DHA. 
There was a clear difference in the AsA/DHA ratio between Norway maple and sycamore embryonic axes (Figure 11A). A relatively unchanged AsA/DHA ratio of 0.75 was reported in sycamore, whereas in Norway maple, the AsA/DHA ratio increased until it reached a value of approximately two at the 16-17th WAF, after which it substantially decreased and remained unchanged until the end of maturation. The cotyledons of Norway maple and sycamore differed markedly between the 18/19th and 21st/22nd WAF. At this time, the AsA/DHA ratio was remarkably high in Norway maple cotyledons and peaked at three, whereas in sycamore, the ratio did not exceed 0.5.

$$
\text { A }
$$

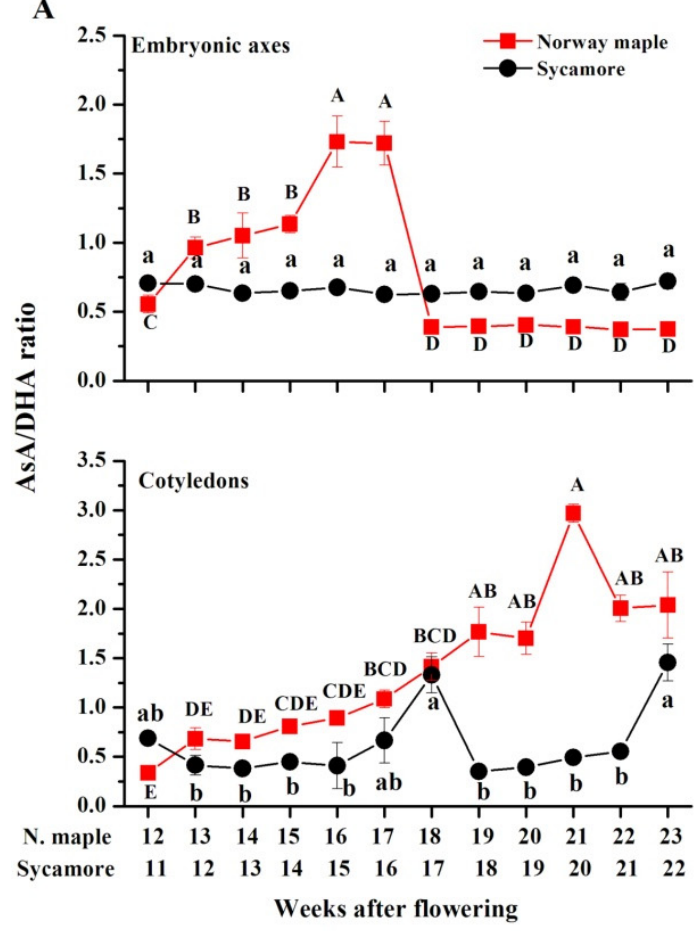

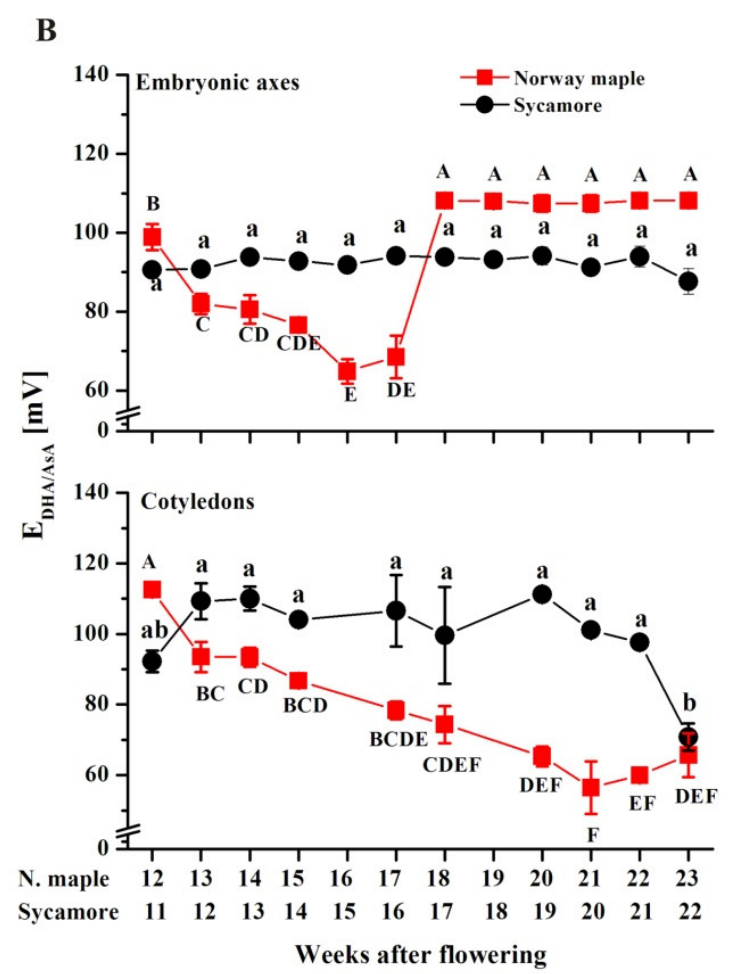

Figure 11. Changes in the ratios of reduced (AsA) to oxidized (DHA) forms of ascorbate (A) and half-cell reduction potential ( $\left.\mathrm{E}_{\mathrm{DHA} / \mathrm{AsA}}\right)$ of ascorbate $(\mathbf{B})$ in the embryonic axes and cotyledons of developing seeds of Norway maple (squares) and sycamore (circles) collected during the 11th-23rd weeks after flowering. Data are the means of three independent replicates \pm the standard error. Statistically significant differences are indicated with different letters (one-way ANOVA, followed by Tukey's test at $p<0.05)$. The capital letters refer to Norway maple.

Changes in concentrations of Asc reduced and oxidized forms, were reflected by the half-cell reduction potential $\left(\mathrm{E}_{\mathrm{DHA} / \mathrm{AsA}}\right)$. The lower the $\mathrm{E}_{\mathrm{DHA} / \mathrm{AsA}}$, the higher the AsA content in the Asc pool (Figure 11B). A clear redox change from highly reduced to highly oxidized was reported uniquely in the embryonic axes of Norway maple seeds at the 17/18th WAF. Interestingly, in cotyledons, $\mathrm{E}_{\mathrm{DHA} / \mathrm{AsA}}$ was substantially lower in most analyzed developmental stages in Norway maple than in sycamore.

\subsection{Glutathione Content}

During Norway maple seed development, the maximal glutathione concentrations were in the range of 20 and $30 \mu$ moles $\mathrm{g}^{-1} \mathrm{DW}$ in embryonic axes and cotyledons, respectively, whereas in sycamore they were in the range of 12 and $10 \mu$ moles $\mathrm{g}^{-1} \mathrm{DW}$, respectively (Figure 12). In both tissues of Norway maple, the total glutathione pool increased at the morphogenesis phase and peaked as maturation started at the 14th WAF. Then, the total glutathione level increased again at the 17th and 20th WAFs in embryonic axes and one week later at the 18th and 21st WAFs in cotyledons. In sycamore embryonic axes, the glutathione content increased until the 16th WAF, and it remained relatively unchanged until the end of maturation. Notably, the average glutathione concentration in embryonic axes was half 
compared to that in Norway maple. In sycamore cotyledons, this level was relatively stable throughout seed development for both the reduced and oxidized forms.

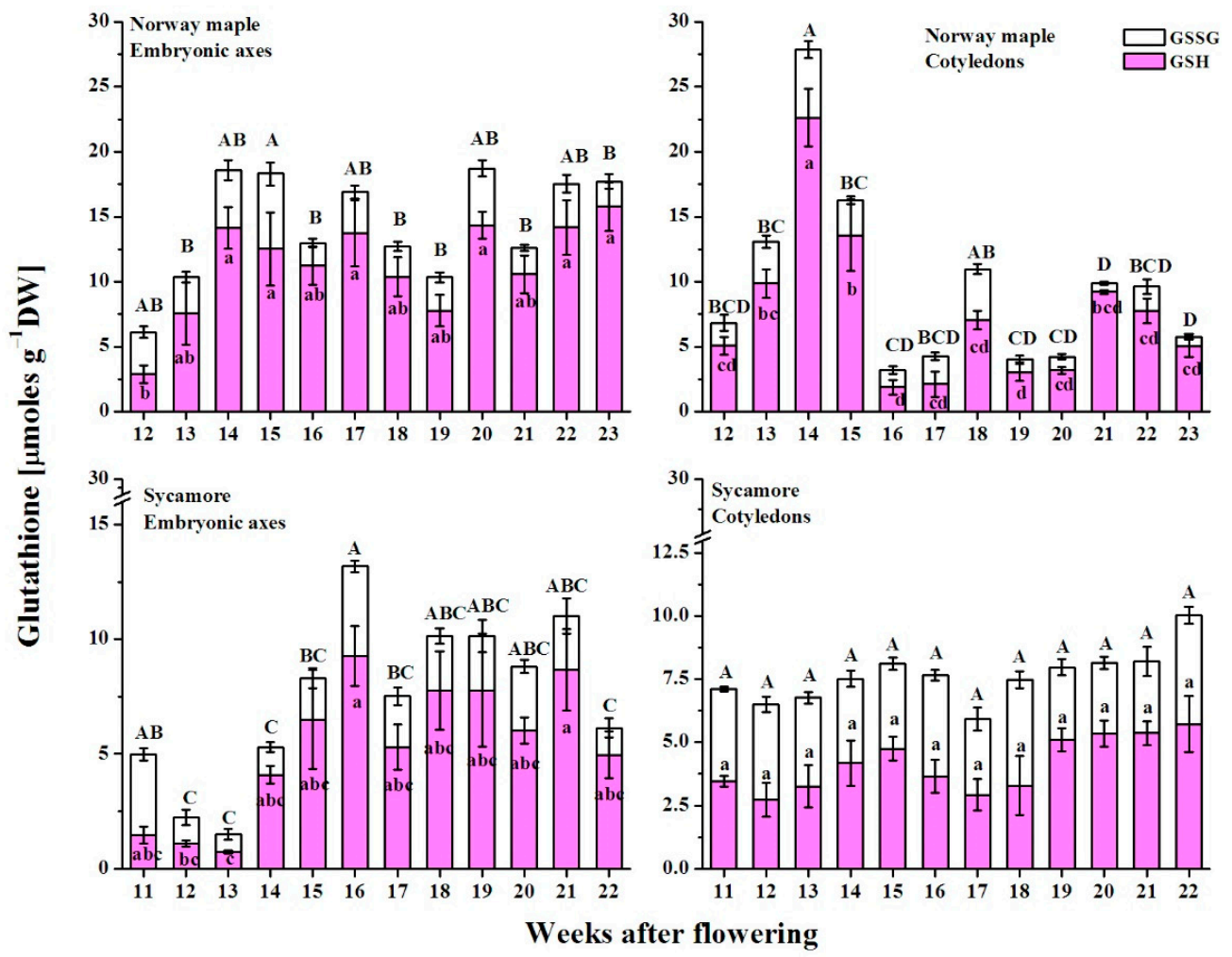

Figure 12. Changes in the levels of the reduced (GSH) and oxidized (GSSG) forms of glutathione reported in the embryonic axes and cotyledons of developing seeds of Norway maple and sycamore collected during the 11th-23rd weeks after flowering. Data are the means of three independent replicates \pm the standard error. Statistically significant differences are indicated with different letters (one-way ANOVA, followed by Tukey's test at $p<0.05)$. The capital letters refer to GSSG.

Glutathione exists in reduced (GSH) and oxidized (GSSG) states. The glutathione degree of oxidation (DO) reported in Norway maple embryonic axes was the highest at the morphogenesis stage, after which it decreased and remained relatively unchanged during seed maturation at a level of approximately $30 \%$ (Figure 13). Sycamore embryonic axes exhibited higher DO values than those in Norway maple embryonic axes, except for at the 14th WAF, with clear change trends. The DO values decreased until the 14th WAF, increased and peaked at the 18th WAF, after which they decreased again, reaching the lowest $\mathrm{DO}$ at the end of maturation. The average $\mathrm{DO}$ in sycamore cotyledons was approximately $60 \%$, whereas a value as high as $60 \%$ was reported in Norway maple cotyledons only at the 16-18th WAF. Except during this period, the DO values in the cotyledons of Norway maple were $40 \%$ and decreased to approximately $20 \%$. The above data clearly indicate that in both embryonic axes and cotyledons, glutathione is more abundant and more reduced in Norway maple than in sycamore.

\subsection{Correlation Analysis}

A correlation coefficient analysis between all measured parameters was performed (Supplementary Materials Figure S5). In Norway maple seeds, the MetO level was positively correlated with changes in the WC and with the activity of NADPH-dependent reductases and ascorbate, but negatively correlated with the protein content and the AsA/DHA ratio. Few links were found in sycamore seeds because only the MetO level was negatively correlated with the $\mathrm{NADP}^{+}$level. The levels of both MsrB1 and MsrB2 in sycamore were negatively correlated with the WC, protein content, AsA and Asc levels, GSH and total glutathione levels. Additionally, the MsrB1 level was correlated with the GSSG level, 
whereas the MsrB2 level was linked to the DHA content. The MsrB2 abundance in Norway maple was positively correlated with the WC, NADPH and NADP levels, as well as with the AsA, DHA, Asc levels, in both embryonic axes and cotyledons. The amount of the MsrB2 redox form with a low molecular mass was correlated with changes in NADH and $\mathrm{NAD}^{+}$concentrations in embryonic axes and with the levels of GSH and GSSG. In contrast, no such relation were noticed for the MsrB2 redox form with a high molecular mass.
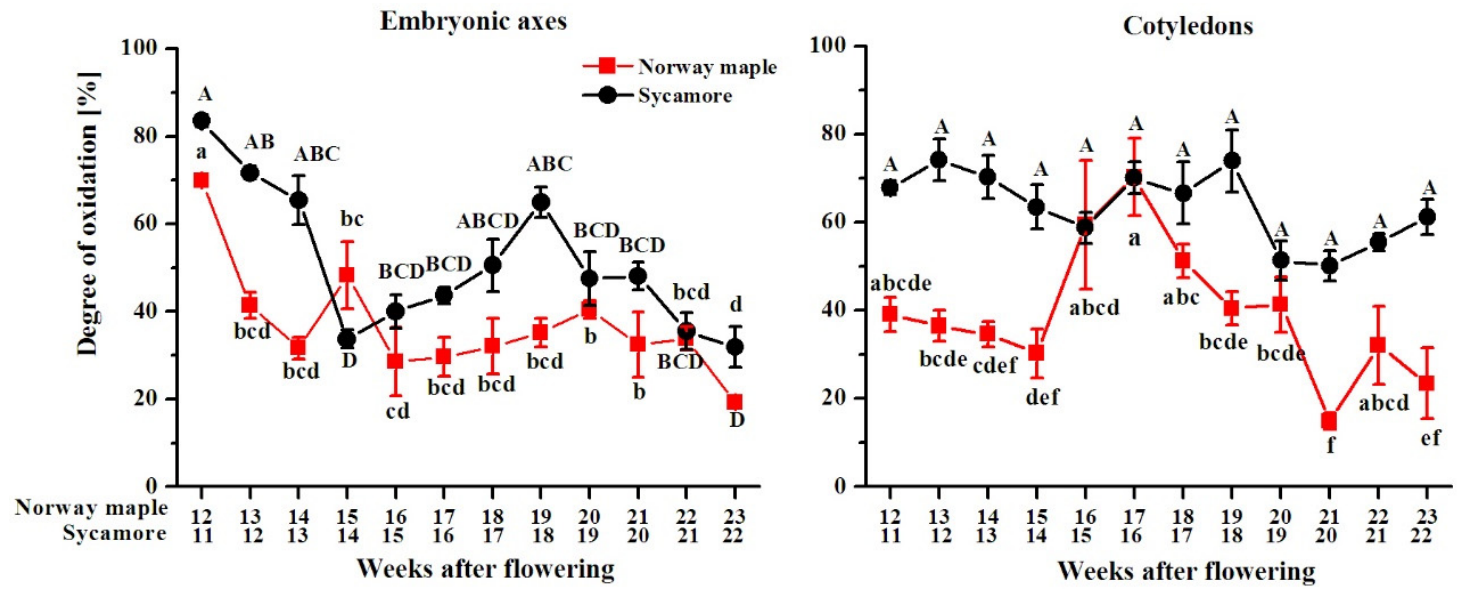

Figure 13. Changes in the degree of oxidation of glutathione in the embryonic axes and cotyledons of developing seeds of Norway maple (squares) and sycamore (circles) collected during the 11th-23rd weeks after flowering. Data are the means of three independent replicates \pm the standard error. Statistically significant differences are indicated with different letters (one-way ANOVA, followed by Tukey's test at $p<0.05)$. The capital letters refer to sycamore.

\section{Discussion}

\subsection{MetO Content in Acer Developing Seeds}

Norway maple and sycamore seeds provides a good model for the comparison of seeds from the same genus with contrasted physiology $[11,12,47,48]$. Here, we used this model for investigating redox biology in developing Acer seeds. Acer seeds gradually lose water throughout the process of maturation $[11,12]$. Here, we observed a decrease in seed hydration level from approximately $80 \%$ to approximately 50\% (Figure 1). Interestingly, the progressive WC decrease was positively correlated with the levels of peptide-bound MetO in Norway maple cotyledons. MetO content depends on efficient ROS removal and proper Msr activity [49-51]. ROS acts as signaling molecules during physiological transitions in seeds [52], and $\mathrm{H}_{2} \mathrm{O}_{2}$ peak levels coincide with the acquisition of desiccation tolerance in Norway maple seeds [12]. Among ROS, $\mathrm{H}_{2} \mathrm{O}_{2}$ oxidizes Met to MetO at a slow rate compared to hydroxyl radicals, which are the most powerful oxidizers of Met [53]. The above data emphasize that the discrete changes in the Met redox status of Norway maple seeds might result from posttranslational modifications that function in signaling pathways involved in the acquisition of desiccation tolerance. Consistently, the MetO level clearly decreased upon desiccation in Norway maple seeds, particularly in the embryonic axes, whereas no change was observed in gradually dehydrating sycamore seeds [17]. Compared with cotyledons, embryonic axes are constitutively protected [54] and exhibit a more active antioxidant system during seed development and drying [11,55]. Thus, seed embryonic axes display much more intense redox changes than do cotyledons, and in Acer species, this phenomenon is likely more pronounced in Norway maple.

\subsection{Role of Plastidial MsrBs in Acer Developing Seeds}

MsrB1 and MsrB2 proteins are highly expressed in photosynthetic Arabidopsis organs [40], and microarray analyses have since confirmed the presence of MsrB2 and MsrB6 transcripts in seeds. 
Châtelain et al. [35] reported that MsrB1 and MsrB2 are expressed in Medicago truncatula seeds. Then, Wojciechowska et al. [17] demonstrated that MsrB2 is present in dried Norway maple and sycamore seeds and that MsrB1 is present only in sycamore seeds, as shown here (Figures 2 and 3). The molecular masses of Arabidopsis MsrB1 and MsrB2 are 17 and 15 kDa, respectively [40]. In Acer seeds, one unique MsrB1 form was revealed, but two approximately 13 and 14 kDa MsrB2 bands were detected (Figure 3B). Western blot analyses of Arabidopsis MsrB2 revealed two distinct bands with higher and lower molecular masses corresponding to oxidized and reduced forms, respectively [40]. In this context, the two bands detected in Norway maple (Figure 3B) probably correspond to oxidized and reduced forms of $\mathrm{MsrB2}$, henceforth referred to as $\mathrm{MsrB2}_{\mathrm{ox}}$ and $\mathrm{MsrB} 2_{\text {red }}$ for the upper and lower bands, respectively. In Arabidopsis, the oxidized form of MsrB2 is predominant in the leaves [40]. In Norway maple, MsrB2 ${ }_{\text {ox }}$ was present throughout seed development, whereas MsrB2 $2_{\text {red }}$ was almost undetectable from the 16th WAF (Figure 3B), indicating a more oxidative environment at the end of maturation. The MsrB2 protein abundance and redox pattern in Norway maple seeds were very different from those in sycamore. In this context, we suggest that MsrB2 might be a new component involved in the redox control of the acquisition of desiccation tolerance in sycamore. Consistently, MsrB2 was reported to be involved in the regulation of redox status during the desiccation phase in Acer orthodox seeds, as its abundance was clearly correlated with changes in MetO and hydroxyl radical levels [17]. In developing M. truncatula seeds, distinct changes in transcript and protein levels revealed complex regulation of MsrB gene expression [35]. Interestingly, levels of both MsrB1 and MsrB2 were correlated with changes in the seed WC level (Supplementary Materials Figure S5). Considering that water stress does not affect MsrB1 and MsrB2 expression in young and mature Arabidopsis leaves [40], the changes in the abundance of MsrB1 and MsrB2 (Figure 3) were probably related to seed development-related events and not to drying down to as much as $50 \%$ WC during maturation. The fact that both the promoters of MsrB1 and MsrB2 include binding sites for transcription factors promoting seed development and morphogenesis support this hypothesis [34,56-58].

Developing seeds of Norway maple and sycamore are green [47] but are completely covered by an opaque brown seed coat. So far, plant MsrB1 and MsrB2 have been reported to be located in the stroma of leaf chloroplasts and protect this organelle against oxidative damage [40]. Given the widespread and non-tissue-specific localization of these proteins (Figure 4) in developing seeds, proplastids are possibly the target organelles of MsrB1 and MsrB2, but this needs further confirmation. MsrA was also found to accumulate in developing Norway maple seeds and was considered involved in dormancy induction [47]. Studies on sycamore seeds revealed that Met metabolism is associated with dormancy breaking [48]. Proteins linked to Met metabolism were significantly up-regulated during the germination of maize mutant seeds tolerant to drought [59]. Increased expression of the MsrA gene coincided with the reinduction of desiccation tolerance in germinated seeds of M. truncatula [60]. All together, these data are consistent with those of Kalemba and Stolarska's report [34], emphasizing that Msrs, notably plastidial ones, are involved in the regulation of numerous plant developmental processes, including during seed formation.

\subsection{Redox Pools in Orthodox and Recalcitrant Acer Seeds}

The redox control of many physiological processes has been demonstrated in plants [22,23]. Previously, the ascorbate-glutathione cycle [11] and Prxs [12] have been characterized as important redox actors in the desiccation tolerance of developing Acer seeds. Here, we demonstrated that other elements of the redox network are involved in the determination of orthodox and recalcitrant phenotypes in two genetically related Acer species. A clear decrease in NAD level throughout maturation was reported uniquely in Norway maple (Figure 7), which is consistent with the progressive deceleration of metabolism observed during this phase in desiccation-tolerant seeds, and not in sensitive ones [5]. Sycamore seeds contained a lower NADP pool than did Norway maple seeds (Figure 8) and exhibited less reducing power in terms of available NADPH. The peak of NADPH-dependent reductase activity was reported in Norway maple seeds at the 14th-15th WAF (Figure 5). Considering that the maximal 
growth of Norway maple embryos occurs at the 14th WAF [47], the activity of NADPH-dependent reductases, seems essential in the control of seed development at this stage. The NADPH/NADP ${ }^{+}$ratio is usually high, favoring the reduced form of NADP [61]. In Norway maple embryonic axes, the ratio peaked at 17th WAF (Figure 9). The signaling role of pyridine nucleotides [62] might be linked to desiccation tolerance acquisition, which was reported to begin in the 18th WAF [11]. Compared with recalcitrant seeds, orthodox Norway maple seeds underwent highly specific redox changes related to nucleotide pools (Figures 6 and 8). The content and redox status of NADH/NAD ${ }^{+}$and NADPH/NADP ${ }^{+}$ were shown to contribute to desiccation tolerance in dried Acer seeds [19]. This report indicates that the differences in $\mathrm{NADH} / \mathrm{NAD}^{+}$and $\mathrm{NADPH} / \mathrm{NADP}^{+}$redox couples are already being formed during maturation when desiccation tolerance is acquired by seeds.

The redox-related differences described in this report enabled us to point the features unique to orthodox Norway maple seeds, which include substantial changes in the MetO level, the presence of reduced and oxidized forms of MsrB2, and a dynamic AsA/DHA ratio, as well as high levels of glutathione, NADPH, and peaks in the activities of NADPH-dependent reductases. Importantly, the MetO level was positively correlated with changes in the activity of reductases, and there was a negative correlation between MetO and both protein levels and the AsA/DHA ratio (Figure S5), indicating that the Met to MetO switch is an element of the redox signaling network active during the Norway maple seed developmental program. These results indicate that the regulation of the Met redox switch in developing seeds is likely more dynamic, and probably more efficient in Norway maple than in sycamore.

\subsection{Regeneration of Msrs}

The Trx-dependent pathway is considered a major regeneration system for plastidial Msrs in plant tissues with active chloroplasts; however, Grx- and GSH/Grx-dependent mechanisms also act in MsrB1 regeneration [36,37]. Since MsrB1 is not reduced by Trxs [31,40], and based on the correlation matrix (Figure S5), it can be speculated that AsA and particularly GSH are involved in MsrB1 regeneration in sycamore seeds via intermediate redox actors. Importantly, AsA levels were the strongest factor correlated with the changes in MsrB2 ${ }_{\text {red }}$ levels in Norway maple. AsA is able to reduce disulfide bridges, including protein mixed disulfides, and the reduction rate is concentration dependent [63]. Additionally, AsA is able to reduce sulfenic acid in proteins [64] and similarly to glutathione promote the reduced form of MsrB2 in Norway maple seeds [17]. However, further studies are required to determine the entire cascade of redox reactions in the regeneration of MsrBs in seeds. Levels of NADPH and NADP ${ }^{+}$ affected the expression of $\mathrm{MsrB}_{2}$ red, whereas the levels of $\mathrm{MsrB}_{2}$ ox were seemingly driven by the NADH and NAD ${ }^{+}$levels (Figure S5). Considering the Foyer-Halliwel-Asada cycle, NADH is required for AsA enzymatic regeneration, whereas NADPH enables GSH restoration [22]. Both pyridine nucleotides significantly affect the levels of $\mathrm{MsrB}_{\text {red, }}$ supporting our hypothesis concerning the involvement of AsA and GSH in MsrB2 reduction. In addition, MsrB2 was found in sycamore embryonic axes predominantly in the oxidized form (Figure $3 \mathrm{~B}$ ), and changes in the level of this form were correlated with AsA and glutathione contents, but not with the contents of NAD(P) forms (Figure S5). All reducing systems for the regeneration of Msrs eventually rely on NADPH availability [65]. In Norway maple, the activity of NADPH-dependent reductases was correlated with changes in all glutathione forms and was highly correlated with the DO of this compound (Figure S5), indicating that the GSH/GSSG switche further affects the reduction capacity in seed tissues. In sycamore cotyledons, NADH and $\mathrm{NAD}^{+}$were positively correlated with components of the ascorbate-glutathione cycle, particularly AsA, and could thus very likely participate in the regeneration system of Msrs. In Norway maple, changes in NADH and NAD ${ }^{+}$levels and in NADPH and $\mathrm{NADP}^{+}$levels were correlated with all Asc forms, supporting that pyridine nucleotides modulate the efficiency of the ascorbate-glutathione cycle (Supplementary Materials Figure S5), which in turn affects the availability of essential reducing agents such as AsA and GSH. Importantly, the redox environment modulated by GSH DO further affected $\mathrm{MsrB}_{\mathrm{ox}}$ expression, indicating that GSH could be an important physiological reducing agent not only 
for MsrB1 [36], but also for MsrB2 in seeds of the two Acer species. Recently, Wojciechowska et al. [17] reported that the amount of reduced form of Norway maple MsrB2 increased when protein extracts were treated with AsA and GSH, supporting this hypothesis.

\section{Conclusions}

Controlled oxidation is critical for developmental transitions in plants, such as those occurring in seeds. In addition to cysteine redox switches, the reversible oxidation of Met to MetO is an important protein posttranslational modification involved in redox signaling [33]. Here, we show that the redox cellular environment strongly differs between developing Norway maple and sycamore seeds, which are categorized as orthodox and recalcitrant, respectively. In Norway maple, the high activity of NADPH-dependent reductases reported around the 14th WAF and the marked reducing conditions seem essential for proper development of orthodox seeds and acquisition of desiccation tolerance. Furthermore, we revealed more dynamic changes in the levels of MetO and MsrB2 in Norway maple than in sycamore, such as the much higher abundance of reduced MsrB2 in the former during the first stages of seed formation. The differences in MsrB2 abundance and redox pattern clearly differentiate Norway maple seeds from sycamore seeds, leading us to propose that this reductase is a new candidate for the establishment of desiccation tolerance. Among the various components involved in redox homeostasis, AsA by acting together with glutathione and reduced form of NAD(P), could provide the reducing power for the regeneration of plastidial MsrB activity in a non-photosynthetic context.

Supplementary Materials: The following are available online at http://www.mdpi.com/2076-3921/9/12/1250/s1, Figure S1: Chromatogram with standards, Figure S2: Representative gels, Figure S3: Soluble proteins, Figure S4: Negative blots, Figure S5: Correlation matrixes.

Author Contributions: Conceptualization, E.M.K. and A.B.-Z.; investigation, E.S., K.B., N.W.; data curation, E.S., K.B., N.W.; writing-original draft preparation, E.S., P.R., E.M.K.; writing-review and editing, E.S., K.B., N.W., A.B.-Z., P.R., E.M.K.; visualization, N.W., E.M.K.; supervision, E.M.K.; funding acquisition, E.M.K. All authors have read and agreed to the published version of the manuscript.

Funding: This research was funded by the National Science Center (Poland) Grant No. 2015/18/E/NZ9/00729.

Acknowledgments: This research was supported by the Institute of Dendrology of the Polish Academy of Sciences.

Conflicts of Interest: The authors declare no conflict of interest.

\section{References}

1. Leprince, O.; Pellizzaro, A.; Berriri, S.; Buitink, J. Late seed maturation: Drying without dying. J. Exp. Bot. 2017, 68, 827-841. [CrossRef]

2. Dekkers, B.J.W.; Costa, M.C.D.; Maia, J.; Bentsink, L.; Ligterink, W.; Hilhorst, H.W.M. Acquisition and loss of desiccation tolerance in seeds: From experimental model to biological relevance. Planta 2015, 241, 563-577. [CrossRef]

3. Roberts, E.H. Predicting the storage life of seeds. Seed Sci. Technol. 1973, 1, 499-514.

4. Berjak, P.; Pammenter, N.W. Implications of the lack of desiccation tolerance in recalcitrant seeds. Front. Plant Sci. 2013, 4, 478. [CrossRef]

5. Walters, C. Orthodoxy, recalcitrance and in-between: Describing variation in seed storage characteristics using threshold responses to water loss. Planta 2015, 242, 397-406. [CrossRef]

6. Oliver, M.J.; Farrant, J.M.; Hilhorst, H.W.M.; Mundree, S.; Williams, B.; Bewley, J.D. Desiccation tolerance: Avoiding cellular damage during drying and rehydration. Annu. Rev. Plant Biol. 2020, 71, 435-460. [CrossRef]

7. Dickie, J.B.; May, K.; Morris, S.V.A.; Titley, S.E. The effects of desiccation on seed survival in Acer platanoides L. and Acer pseudoplatanus L. Seed Sci. Res. 1991, 1, 149-162. [CrossRef]

8. Giarola, V.; Hou, Q.; Bartels, D. Angiosperm plant desiccation tolerance: Hints from transcriptomics and genome sequencing. Trends Plant Sci. 2017, 22, 705-717. [CrossRef]

9. Sershen, N.; Varghese, B.; Naidoo, C.; Pammenter, N.W. The use of plant stress biomarkers in assessing the effects of desiccation in zygotic embryos from recalcitrant seeds: Challenges and considerations. Plant Biol. 2016, 18, 433-444. [CrossRef] [PubMed] 
10. Farrant, J.M.; Pammenter, N.W.; Berjak, P.; Walters, C. Subcellular organization and metabolic activity during the development of seeds that attain different levels of desiccation tolerance. Seed Sci. Res. 1997, 7, 135-144. [CrossRef]

11. Pukacka, S.; Ratajczak, E. Ascorbate and glutathione metabolism during development and desiccation of orthodox and recalcitrant seeds of the genus Acer. Funct. Plant Biol. 2007, 34, 601-613. [CrossRef] [PubMed]

12. Ratajczak, E.; Staszak, A.M.; Wojciechowska, N.; Bagniewska-Zadworna, A.; Dietz, K.J. Regulation of thiol metabolism as a factor that influences the development and storage capacity of beech seeds. J. Plant Physiol. 2019, 239, 61-70. [CrossRef] [PubMed]

13. Hong, T.D.; Ellis, R.H. A comparison of maturation drying, germination, and desiccation tolerance between developing seeds of Acer pseudoplatanus L. and Acer platanoides L. New Phytol. 1990, 116, 589-596. [CrossRef]

14. Greggains, V.; Finch-Savage, W.E.; Quick, W.P.; Atherton, N.M. Putative desiccation tolerance mechanisms in orthodox and recalcitrant seeds of the genus Acer. Seed Sci. Res. 2000, 10,317-327. [CrossRef]

15. Kalemba, E.M.; Pukacka, S. association of protective proteins with dehydration and desiccation of orthodox and recalcitrant category seeds of three Acer genus species. J. Plant Growth Regul. 2012, 31, 351-362. [CrossRef]

16. Ratajczak, E.; Stroeher, E.; Oelze, M.-L.; Kalemba, E.M.; Pukacka, S.; Dietz, K.-J. The involvement of the mitochondrial peroxiredoxin PRXIIF in defining physiological differences between orthodox and recalcitrant seeds of two Acer species. Funct. Plant Biol. 2013, 40, 1005-1017. [CrossRef]

17. Wojciechowska, N.; Alipour, S.; Stolarska, E.; Bilska, K.; Rey, P.; Kalemba, E.M. Peptide-bound methionine sulfoxide (MetO) levels and MsrB2 abundance are differentially regulated during the desiccation phase in contrasted Acer seeds. Antioxidants 2020, 9, 391. [CrossRef]

18. Pukacka, S. Characteristics of seed development of Norway maple (Acer platanoides L.) and sycamore (Acer pseudoplatanus L.). Arboretum Kornickie 1998, 43, 97-104. (In Polish)

19. Alipour, S.; Wojciechowska, N.; Stolarska, E.; Bilska, K.; Kalemba, E.M. NAD(P)-driven redox status contributes to desiccation tolerance in Acer seeds. Plant Cell Physiol. 2020, 61, 1158-1167. [CrossRef]

20. Gakière, B.; Hao, J.; de Bont, L.; Pétriacq, P.; Nunes-Nesi, A.; Fernie, A.R. NAD+ biosynthesis and signaling in plants. Crit. Rev. Plant Sci. 2018, 37, 259-307. [CrossRef]

21. Pétriacq, P.; Ton, J.; Patrit, O.; Tcherkez, G.; Gakière, B. NAD acts as an integral regulator of multiple defense layers. Plant Physiol. 2016, 172, 1465-1479. [CrossRef] [PubMed]

22. Foyer, C.H.; Noctor, G. Ascorbate and glutathione: The heart of the redox hub. Plant Physiol. 2011, 155, 2-18. [CrossRef]

23. De Simone, A.; Hubbard, R.; de la Torre, N.V.; Velappan, Y.; Wilson, M.; Considine, M.J.; Soppe, W.J.J.; Foyer, C.H. Redox changes during the cell cycle in the embryonic root meristem of Arabidopsis thaliana. Antioxid. Redox Signal. 2017, 27, 1505-1519. [CrossRef] [PubMed]

24. Kocsy, G. Die or survive? Redox changes as seed viability markers. Plant Cell Environ. 2015, 38, 1008-1010. [CrossRef] [PubMed]

25. Huang, H.; Ullah, F.; Zhou, D.-X.; Yi, M.; Zhao, Y. Mechanisms of ROS Regulation of plant development and stress responses. Front. Plant Sci. 2019, 10, 800. [CrossRef]

26. Jacques, S.; Ghesquière, B.; Van Breusegem, F.; Gevaert, K. Plant proteins under oxidative attack. Proteomics 2013, 13, 932-940. [CrossRef] [PubMed]

27. Moskovitz, J. Methionine sulfoxide reductases: Ubiquitous enzymes involved in antioxidant defense, protein regulation, and prevention of aging-associated diseases. Biochim. Biophys. Acta 2005, 1703, 213-219. [CrossRef]

28. Luo, S.; Levine, R.L. Methionine in proteins defends against oxidative stress. FASEB J. 2009, $23,464-472$. [CrossRef]

29. Achilli, C.; Ciana, A.; Minetti, G. The discovery of methionine sulfoxide reductase enzymes: An historical account and future perspectives. Biofactors 2015, 41, 135-152. [CrossRef]

30. Rouhier, N.; Couturier, J.; Jacquot, J.-P. Genome-wide analysis of plant glutaredoxin systems. J. Exp. Bot. 2006, 57, 1685-1696. [CrossRef]

31. Tarrago, L.; Laugier, E.; Rey, P. Protein-repairing methionine sulfoxide reductases in photosynthetic organisms: Gene organization, reduction mechanisms, and physiological roles. Mol. Plant 2009, 2, 202-217. [CrossRef] [PubMed]

32. Peng, M.; Chang, Y.; Chu, G.; Wang, M. Low-temperature tolerance and transcriptome analyses during seed germination of Anabasis aphylla. J. Plant Interact. 2019, 14, 254-264. [CrossRef] 
33. Rey, P.; Tarrago, L. Physiological roles of plant methionine sulfoxide reductases in redox homeostasis and signaling. Antioxidants 2018, 7, 114. [CrossRef] [PubMed]

34. Kalemba, E.M.; Stolarska, E. Regulation of gene expression of methionine sulfoxide reductases and their new putative roles in plants. Int. J. Mol. Sci. 2019, 20, 1309. [CrossRef] [PubMed]

35. Châtelain, E.; Satour, P.; Laugier, E.; Ly Vu, B.; Payet, N.; Rey, P.; Montrichard, F. Evidence for participation of the methionine sulfoxide reductase repair system in plant seed longevity. Proc. Natl. Acad. Sci. USA 2013, 110, 3633-3638. [CrossRef]

36. Tarrago, L.; Laugier, E.; Zaffagnini, M.; Marchand, C.; Le Maréchal, P.; Rouhier, N.; Lemaire, S.D.; Rey, P. Regeneration mechanisms of Arabidopsis thaliana methionine sulfoxide reductases B by glutaredoxins and thioredoxins. J. Biol. Chem. 2009, 284, 18963-18971. [CrossRef]

37. Couturier, J.; Vignols, F.; Jacquot, J.-P.; Rouhier, N. Glutathione- and glutaredoxin-dependent reduction of methionine sulfoxide reductase A. FEBS Lett. 2012, 586, 3894-3899. [CrossRef]

38. Bradford, M.M. A rapid and sensitive method for the quantitation of microgram quantities of protein utilizing the principle of protein-dye binding. Anal. Biochem. 1976, 72, 248-254. [CrossRef]

39. Baxter, J.H.; Lai, C.-S.; Phillips, R.R.; Dowlati, L.; Chio, J.J.; Luebbers, S.T.; Dimler, S.R.; Johns, P.W. Direct determination of methionine sulfoxide in milk proteins by enzyme hydrolysis/high-performance liquid chromatography. J. Chromatogr. A 2007, 1157, 10-16. [CrossRef]

40. Vieira Dos Santos, C.; Cuiné, S.; Rouhier, N.; Rey, P. The Arabidopsis plastidic methionine sulfoxide reductase $B$ proteins. sequence and activity characteristics, comparison of the expression with plastidic methionine sulfoxide reductase A, and induction by photooxidative stress. Plant Physiol. 2005, 138, 909-922. [CrossRef]

41. Wojciechowska, N.; Smugarzewska, I.; Marzec-Schmidt, K.; Zarzyńska-Nowak, A.; Bagniewska-Zadworna, A. Occurrence of autophagy during pioneer root and stem development in Populus trichocarpa. Planta 2019, 250, 1789-1801. [CrossRef] [PubMed]

42. Queval, G.; Noctor, G. A plate reader method for the measurement of NAD, NADP, glutathione, and ascorbate in tissue extracts: Application to redox profiling during Arabidopsis rosette development. Anal. Biochem. 2007, 363, 58-69. [CrossRef] [PubMed]

43. Hewitt, E.J.; Dickes, G.J. Spectrophotometric measurements on ascorbic acid and their use for the estimation of ascorbic acid and dehydroascorbic acid in plant tissues. Biochem. J. 1961, 78, 384-391. [CrossRef] [PubMed]

44. Meyer, A.J.; Hell, R. Glutathione homeostasis and redox-regulation by sulfhydryl groups. Photosyn. Res. 2005, 86, 435-457. [CrossRef] [PubMed]

45. R Core Team. A Language and Environment for Statistical Computing; R Foundation for Statistical Computing: Vienna, Austria, 2013.

46. Wei, T.; Simko, V. R Package Corrplot: Visualization of a Correlation Matrix. (Version 0.84). Available online: https://github.com/taiyun/corrplot (accessed on 11 May 2020).

47. Staszak, A.M.; Pawłowski, T.A. Proteomic analysis of embryogenesis and the acquisition of seed dormancy in Norway maple (Acer platanoides L.). Int. J. Mol. Sci. 2014, 15, 10868-10891. [CrossRef]

48. Pawłowski, T.A.; Staszak, A.M. Analysis of the embryo proteome of sycamore (Acer pseudoplatanus L.) seeds reveals a distinct class of proteins regulating dormancy release. J. Plant Physiol. 2016, 195, 9-22. [CrossRef]

49. Ferguson, D.L.; Burke, J.J. Methionyl sulfoxide content and protein-methionine-S-oxide reductase activity in response to water deficits or high temperature. Physiol. Plant 1994, 90, 253-258. [CrossRef]

50. Laugier, E.; Tarrago, L.; Vieira Dos Santos, C.; Eymery, F.; Havaux, M.; Rey, P. Arabidopsis thaliana plastidial methionine sulfoxide reductases B, MSRBs, account for most leaf peptide MSR activity and are essential for growth under environmental constraints through a role in the preservation of photosystem antennae. Plant J. 2010, 61, 271-282. [CrossRef]

51. Jacques, S.; Ghesquière, B.; De Bock, P.-J.; Demol, H.; Wahni, K.; Willems, P.; Messens, J.; Van Breusegem, F.; Gevaert, K. Protein methionine sulfoxide dynamics in Arabidopsis thaliana under oxidative stress. Mol. Cell. Proteom. 2015, 14, 1217-1229. [CrossRef]

52. Bailly, C. The signalling role of ROS in the regulation of seed germination and dormancy. Biochem. J. 2019, 476, 3019-3032. [CrossRef]

53. Drazic, A.; Winter, J. The physiological role of reversible methionine oxidation. Biochim. Biophys. Acta 2014, 1844, 1367-1382. [CrossRef] [PubMed] 
54. Leprince, O.; Buitink, J.; Hoekstra, F.A. Axes and cotyledons of recalcitrant seeds of Castanea sativa Mill. exhibit contrasting responses of respiration to drying in relation to desiccation sensitivity. J. Exp. Bot. 1999, 50, 1515-1524. [CrossRef]

55. Roach, T.; Ivanova, M.; Beckett, R.P.; Minibayeva, F.V.; Green, I.; Pritchard, H.W.; Kranner, I. An oxidative burst of superoxide in embryonic axes of recalcitrant sweet chestnut seeds as induced by excision and desiccation. Physiol. Plant 2008, 133, 131-139. [CrossRef] [PubMed]

56. Alonso-Peral, M.M.; Li, J.; Li, Y.; Allen, R.S.; Schnippenkoetter, W.; Ohms, S.; White, R.G.; Millar, A.A. The microRNA159-regulated GAMYB-like genes inhibit growth and promote programmed cell death in Arabidopsis. Plant Physiol. 2010, 154, 757-771. [CrossRef] [PubMed]

57. Kunieda, T.; Mitsuda, N.; Ohme-Takagi, M.; Takeda, S.; Aida, M.; Tasaka, M.; Kondo, M.; Nishimura, M.; Hara-Nishimura, I. NAC family proteins NARS1/NAC2 and NARS2/NAM in the outer integument regulate embryogenesis in Arabidopsis. Plant Cell 2008, 20, 2631-2642. [CrossRef] [PubMed]

58. Furuta, K.M.; Yadav, S.R.; Lehesranta, S.; Belevich, I.; Miyashima, S.; Heo, J.; Vatén, A.; Lindgren, O.; De Rybel, B.; Van Isterdael, G.; et al. Plant development. Arabidopsis NAC45/86 direct sieve element morphogenesis culminating in enucleation. Science 2014, 345, 933-937. [CrossRef] [PubMed]

59. Liu, Z.; Marella, C.B.N.; Hartmann, A.; Hajirezaei, M.-R.; von Wirén, N. An age-dependent sequence of physiological processes defines developmental root senescence. Plant Physiol. 2019, 181, 993-1007. [CrossRef]

60. Buitink, J.; Leger, J.J.; Guisle, I.; Vu, B.L.; Wuillème, S.; Lamirault, G.; Le Bars, A.; Le Meur, N.; Becker, A.; Küster, H.; et al. Transcriptome profiling uncovers metabolic and regulatory processes occurring during the transition from desiccation-sensitive to desiccation-tolerant stages in Medicago truncatula seeds. Plant J. 2006, 47, 735-750. [CrossRef]

61. Pollak, N.; Dölle, C.; Ziegler, M. The power to reduce: Pyridine nucleotides-Small molecules with a multitude of functions. Biochem. J. 2007, 402, 205-218. [CrossRef]

62. Decros, G.; Beauvoit, B.; Colombié, S.; Cabasson, C.; Bernillon, S.; Arrivault, S.; Guenther, M.; Belouah, I.; Prigent, S.; Baldet, P.; et al. Regulation of pyridine nucleotide metabolism during tomato fruit development through transcript and protein profiling. Front. Plant Sci. 2019, 10, 1201. [CrossRef]

63. Giustarini, D.; Dalle-Donne, I.; Colombo, R.; Milzani, A.; Rossi, R. Is ascorbate able to reduce disulfide bridges? A cautionary note. Nitric Oxide-Biol. CH 2008, 19, 252-258. [CrossRef] [PubMed]

64. Anschau, V.; Ferrer-Sueta, G.; Aleixo-Silva, R.L.; Bannitz Fernandes, R.; Tairum, C.A.; Tonoli, C.C.C.; Murakami, M.T.; de Oliveira, M.A.; Netto, L.E.S. Reduction of sulfenic acids by ascorbate in proteins, connecting thiol-dependent to alternative redox pathways. Free Radic. Biol. Med. 2020, 156, 207-216. [CrossRef] [PubMed]

65. Kim, H.-Y. The methionine sulfoxide reduction system: Selenium utilization and methionine sulfoxide reductase enzymes and their functions. Antioxid. Redox Signal. 2013, 19, 958-969. [CrossRef] [PubMed]

Publisher's Note: MDPI stays neutral with regard to jurisdictional claims in published maps and institutional affiliations.

(C) 2020 by the authors. Licensee MDPI, Basel, Switzerland. This article is an open access article distributed under the terms and conditions of the Creative Commons Attribution (CC BY) license (http://creativecommons.org/licenses/by/4.0/). 